\title{
Monopoly Insurance and Endogenous Information
}

\author{
Johan N. M. Lagerlöf \\ Christoph Schottmüller* \\ University of Copenhagen \\ University of Copenhagen and TILEC
}

August 2, 2015

\begin{abstract}
We study a monopoly insurance model with endogenous information acquisition. Through a continuous effort choice, consumers determine the precision of a privately observed signal that is informative about their accident risk. The equilibrium effort is, depending on parameter values, either zero (implying symmetric information) or positive (implying privately informed consumers). Regardless of the nature of the equilibrium, all offered contracts, also at the top, involve underinsurance. The reason is that underinsurance at the top discourages information gathering. We identify a missorting effect that explains why the insurer wants to discourage information acquisition. Moreover, a public policy that decreases the information gathering costs can hurt both parties. Lower such costs can harm consumers because the insurer adjusts the optimal contract menu in an unfavorable manner.
\end{abstract}

Keywords: asymmetric information, information acquisition, insurance, screening, adverse selection

JEL codes: D82, I13

*Address to both authors: Department of Economics, University of Copenhagen, Øster Farimagsgade 5, Building 26, DK-1353 Copenhagen K, Denmark; email: johan.lagerlof@econ.ku.dk and christoph.schottmueller@econ.ku.dk. We are grateful for helpful comments from three anonymous referees, the editor Hanming Fang, and seminar audiences at the University of Copenhagen, Humboldt University Berlin, TILEC (at Tilburg University), EARIE 2013 (in Évora, Portugal), EEA 2014 (in Toulouse, France), and RES 2015 (in Manchester, U.K.). 


\section{Introduction}

Following the seminal papers of Stiglitz (1977) and Rothschild and Stiglitz (1976), a very large part of the insurance literature studies selection in markets where consumers have private information about their risk; see Dionne et al. (2013) for a recent survey of this literature. The main justification for the assumption of private information about risk is that consumers typically know their own life style and environment better than the insurer. While this is certainly true, knowing about one's own life style and environment does not necessarily mean that one knows about one's risk status: In order to learn about that, a consumer must also find out how life style and environment affect risk. In the age of the internet, it is definitely possible to acquire such information. Doing that, however, will require time and effort and acquired information might be incorrect or misinterpreted.

In this paper, we study an insurance model in which consumers initially have no private information concerning their risk status. However, by exerting costly effort they can obtain a private and noisy signal about the risk. Our motivation for undertaking the study is threefold. First, we believe the situation we describe has practical relevance: Consumers in real world markets search for information about their risk before buying insurance, and their ability and inclination to do so is likely to increase even more in the future as information technologies improve. Second, it is important to assess whether the traditional models of risk selection are robust in the following sense: Are the main results still valid if consumers must exert effort in order to acquire private information? Can traditional insurance models be interpreted as models where the costs of information acquisition are very low? Third, the topic of information acquisition by consumers is relevant for policy. In particular, what are the welfare effects of policies that make it easier for consumers to acquire information? While policymakers often associate better informed consumers with higher (consumer) welfare,${ }^{1}$ such a link is far from obvious in situations where (the gathering of) information may exacerbate informational asymmetries. If this is the case, public policies that facilitate information acquisition might be detrimental to (consumer) welfare because they increase informational distortions.

As an example of a situation that we have in mind, consider the health insurance market. Suppose a consumer, prior to purchasing a health insurance policy, has the opportunity to acquire information about his health risk. This consumer may know-in

\footnotetext{
${ }^{1}$ For example, the chair of Consumer Focus, a public consumer organization in the U.K., argues that "Well informed consumers make markets work better. This is good for consumers, good for economic growth and good for Britain." See http://www.consumerfocus.org.uk/news/ greater-clarity-on-consumer-rights-welcomed-by-consumer-focus (accessed June 10, 2015).
} 
broad terms - that his smoking and exercise habits affect his risk of developing a cardiovascular disease. But in order to learn about how substantial the increase in risk is if he smokes five cigarettes a day, and whether this effect is offset by his weekly running routine, an average consumer would have to gather more information. If the consumer gathers the required information and if the insurer does not know about the details of the consumer's life style and habits, ${ }^{2}$ the consumer will end up with private information about his health risk. Another story would be that the consumer knows that one grandparent and one of his aunts are affected by a particular genetic disorder, but his parents are not. To understand how these circumstances affect the consumer's own health risk, he must learn how the inheritance pattern of the genetic disorder works. ${ }^{3}$ After learning the inheritance pattern, he will indeed have private information about his risk as long as the insurance company does not know the health history of the consumer's family. The health insurance sector is also a suitable example to illustrate our policy motivation, as there are many public institutions that provide health information. The European Commission's Directorate-General for Health and Consumers (DG-SANCO) mentions, as one of its focus points, "EU-wide collation and analysis of health data [...] to provide citizens and health professionals with the information they seek" (http://ec.europa. eu/dgs/health_consumer/general_info/mission_en.html; accessed June 10, 2015).

In our formal analysis, we develop a monopoly insurance model in which consumers have the opportunity to, privately and covertly, gather information about their (health) risks. In particular, after having observed the insurance company's offered menu of insurance policies, a consumer makes a continuous effort choice that determines the informativeness of a signal about his true risk (which is either "low" or "high"). The consumer observes the signal, which is binary, and then either chooses a policy from the menu or decides to remain uninsured. We characterize the equilibrium menu of insurance policies and study the comparative statics of a change in information acqui-

\footnotetext{
${ }^{2}$ It may also be that - although having some information about those things - the insurer is legally prohibited from making the insurance policy contingent on them. We should further point out that insurers often have a lot of (private) information and use this information to discriminate between different risk groups. Everything we say about the private information of the consumer should be interpreted as being conditional on being in a certain risk group. To illustrate, the recent "ObamaCare" reforms in the U.S. established that premiums of marketplace insurance plans are allowed to depend on location, age, family size, and tobacco use only. Discrimination along any other categories, like for example gender or health status, is prohibited. The consumer population in our analysis could then be all single, non-smoking men of age forty living in a given zip code area.

${ }^{3}$ If, in the example, we are talking about Huntington's disease, this particular health history would be favorable for the consumer, as Huntington's disease has an autosomal dominant inheritance pattern. If, however, we are talking about Wilson's disease, then the consumer would be at an increased risk as the inheritance pattern is autosomal recessive.
} 
sition costs. Such a cost change can be interpreted as a public policy that facilitates consumer learning about (health) risks. Examples of public policies that we have in mind include informational campaigns, the launch of an information website, and the funding of phone lines with expert advice.

The equilibrium of the model belongs to one of three categories: pooling - the consumer is induced to choose a zero effort, which means that there is effectively only one type of agent in the model; exclusion - the consumer chooses some positive effort and then purchases an insurance only if observing a high-risk signal; and separation - the consumer chooses some positive effort and then buys an insurance with high (low, respectively) coverage if observing a high-risk (low-risk) signal. We show, by means of examples, that there are parameter values for which an equilibrium belonging to each one of these categories exists.

We further show that, regardless of which of the three categories the equilibrium belongs to, all contracts in the offered menu involve underinsurance. This means, in particular, that the famous "no distortion at the top" property does not hold in our model. Lowering the coverage of the high-coverage contract makes the offered insurance contracts more similar and, therefore, discourages information gathering. We show that badly informed consumers increase the insurer's profit as a result of a missorting effect: As the precision of the consumer's signal drops, the probability that a consumer whose true risk is high receives a low-risk signal (and therefore buys a low-coverage contract) increases; similarly, a lower signal precision also leads to a higher likelihood that a lowrisk consumer receives a high-risk signal (and therefore buys a high-coverage contract). This kind of missorting increases the insurer's profit because consumers buying the highcoverage (low-coverage) contract have a lower (higher) risk. Hence, the indemnities that the insurer must pay are lower in expectation.

Finally, we show that a reduction in the consumer's information gathering costs can hurt both the consumer and the insurer. The result that the consumer is hurt is probably the more surprising one. The reason is that the distortion in the offered contracts changes as the costs of information gathering change. Technically speaking, lower information gathering costs exacerbate the consumer's threat to acquire more information (which corresponds to a binding constraint in the insurer's maximization problem). This threat is mitigated by distorting the high-coverage contract which can lower consumer surplus.

Doherty and Thistle (1996) study a question that is related to the one we study. They model a perfectly competitive (health) insurance market in which some consumers do not know their risk type but can (perfectly) learn this by taking a test. One example that the authors suggest is HIV testing. The focus of their paper is the effect of observ- 
ability and verifiability of test taking and test outcome. This leads to policy questions concerning the regulation of contractible information in health insurance contracts. The model of Doherty and Thistle (1996) has been extended by adding prevention decisions (Bardey and De Donder, 2013) and early treatment possibilities (Peter et al., 2012). ${ }^{4}$ Our paper focuses on another policy question (namely, the welfare effects of facilitating information acquisition) and a different model setup (monopoly, continuous effort, and noisy signal).

In a companion paper (Lagerlöf and Schottmüller, 2014), we study an alternative setting in which the information gathering decision is binary (e.g., deciding whether to take a genetic test). The application (test taking vs. information search), driving forces, and results differ in several ways from those in the present paper; for example, in the companion paper other constraints are binding, which implies that contracts do not have to be distorted and consumers cannot lose from marginal reductions of the test taking costs.

Models with endogenous information acquisition have also been analyzed in other frameworks: The literature covers procurement settings - see, for example, Crémer and Khalil (1992) and Crémer et al. (1998)—but also auctions (Persico, 2000; Shi, 2012) and implementation of efficient allocations à la Vickrey-Clark-Groves (Bergemann and Välimäki, 2002). Within this literature, the paper most closely related to our model is probably Szalay (2009), who analyzes a procurement setting in which a firm, by exerting effort, can choose the extent to which a privately observed signal is informative about the firm's marginal cost. As in our model, the effort choice is continuous. An important difference between his procurement and our insurance setting is that only in the procurement case knowledge of the agent's type is required to achieve the first best allocation. In an insurance setting, the first best allocation is always, for all types, full coverage. This implies that exerting effort is wasteful from a first best point of view. Szalay uses a first-order approach - that is, he focuses on situations where the agent's effort choice problem has an interior solution. Given that the first best effort is zero in the insurance setting, we should allow for the possibility that also the optimal (second best) effort is zero. Hence, we must take global constraints into account and cannot restrict ourselves to a pure first-order approach. The wastefulness of effort also gives an intuitive explanation for why the equilibrium value of information for the agent is

\footnotetext{
${ }^{4}$ Broadly related to these papers is also Ligon and Thistle (1996), which is a monopoly model of health insurance in which consumers can take preventive effort. While information acquisition is not modeled, the authors compare a scenario where agents know their risk with a scenario where they do not know their risk.
} 
positive in Szalay (2009) but zero in our setup. ${ }^{5}$

Crémer and Khalil (1992) study a procurement setting where effort is wasteful. The agent in their model can acquire costly and perfect information before deciding whether he participates (which is after seeing the contract menu). If he participates, he learns his type costlessly (even if he did not acquire information earlier) and then chooses a contract from the menu. The costly information acquisition is therefore unnecessary for efficient production but allows the agent to extract rents. The agent in our model will not learn his type if he does not gather information and therefore the participation and contract choice decisions coincide in our model. This implies that not only ex ante but also interim participation constraints are relevant in our setting. Furthermore, our effort decision is continuous instead of binary. In contrast to Crémer and Khalil (1992), information acquisition can indeed occur in equilibrium in our model.

The paper is organized as follows. The next section describes our model. We then solve the model using backward induction. Section 3 analyzes the contract choice of the agent, section 4 looks at the agent's optimal effort choice, and section 5 examines the optimal menu design problem of the insurer. In section 6 , we return to the policy questions raised in the text above and show, inter alia, that a lower information acquisition cost can lead to both lower consumer surplus and lower profits. Section 7 concludes. The appendix contains proofs and details about our numerical examples.

\section{Model}

The principal of the model is a risk neutral and profit-maximizing insurance monopolist. The agent is a risk averse consumer who faces an accident risk and maximizes expected utility. We denote the consumer's initial wealth by $w>0$, and we assume that an accident leads to (the equivalent of) a monetary loss, or damage, $D \in(0, w)$. An insurance contract specifies a premium $p$ and an indemnity $R$ that is paid in case the loss occurs. Thus, if the consumer purchases a contract $(p, R)$ and if we let $u$ be his Bernoulli utility function (with $u^{\prime}>0$ and $u^{\prime \prime}<0$ ), then the consumer's utility equals $u(w-D-p+R)$ in case of a loss and $u(w-p)$ otherwise.

The accident occurs with the exogenous probability $\theta \in(0,1)$. This probability is either high $\left(\theta=\theta^{h}\right)$ or low $\left(\theta=\theta^{l}\right.$, with $\left.\theta^{l}<\theta^{h}\right)$. Initially the value is unknown to

\footnotetext{
${ }^{5}$ The fact that Szalay (2009) assumes a very rich setup with both a continuous effort space and signal space means that he can "say very little about the optimal choice of effort to implement" (p. 593), although he does show that zero effort is never optimal. A contribution of our paper is to study the consequences of a continuous effort choice in a screening model with endogenous information acquisition, but with a simpler signal space that allows us to characterize the optimal effort choice.
} 
both parties - we let $\alpha_{i}=\operatorname{Pr}\left[\theta=\theta^{i}\right] \in(0,1)$, for $i \in\{l, h\}$, denote the insurer's and the consumer's common prior. The consumer, however, privately observes a binary signal $\sigma \in\left\{\sigma^{l}, \sigma^{h}\right\}$, which may be informative about $\theta$. The informativeness of the signal is determined by the consumer's effort $e \geq 0$. The larger is $e$, the higher is the correlation between the signal and the true accident probability.

The timing of events is as follows.

1. Nature determines the value of the accident probability $\theta \in\left\{\theta^{l}, \theta^{h}\right\}$, according to the prior distribution $\operatorname{Pr}\left[\theta=\theta^{i}\right]=\alpha_{i}$. Neither the insurer nor the consumer can observe the realization of this draw.

2. The insurer chooses a menu of insurance contracts $(p, R)$, which is then observed by the consumer.

3. The consumer chooses an effort level $e \geq 0$ and then observes a signal $\sigma \in\left\{\sigma^{l}, \sigma^{h}\right\}$. The insurer cannot observe the effort level or the signal.

4. Given the signal $\sigma$ and the effort choice $e$, the consumer uses Bayes' rule to form an interim belief about his risk and then picks one insurance contract from the menu (or remains uninsured).

The signal technology works as follows. Given effort $e$, the signal $\sigma^{i}$ that the consumer observes is drawn from the prior distribution with probability $1-g(e)$, and it reflects the true risk $\theta^{i}$ with probability $g(e)$. This is illustrated in figure 1 . The function $g$ is continuous and two times continuously differentiable. Moreover, the signal is uninformative if no effort is exerted $(g(0)=0)$, it is more informative if more effort is exerted $\left(g^{\prime}(e)>0\right)$, and the marginal effect of effort is weakly decreasing $\left(g^{\prime \prime}(e) \leq 0\right)$. This setup implies that the probability of indeed being (say) a high-risk consumer, conditional on having received a high signal, is increasing in the effort level. ${ }^{6}$ Still, for all $e \geq 0$, the unconditional probability of a receiving a signal $i$ equals the prior (i.e., $\operatorname{Pr}\left[\sigma=\sigma^{i}\right]=\alpha_{i}$ ). This latter property holds because the function $g$ is the same regardless of whether a consumer's true risk is low or high. ${ }^{7}$

\footnotetext{
${ }^{6}$ One can check that $\operatorname{Pr}\left[\theta=\theta^{i} \mid \sigma=\sigma^{i}\right]=\alpha_{i}+\left(1-\alpha_{i}\right) g(e)$, which is indeed increasing in $e$.

${ }^{7}$ Making this assumption greatly simplifies our analysis. It is not clear (to us) whether it is, in real-world insurance markets, more difficult to obtain information about one's type if one is truly a low-risk type or if one is truly a high-risk type. Therefore, assuming that the level of difficulty is the same strikes us as a reasonable simplification. We further note two things. First, what we require for our analysis is that the $\beta_{i}(e)$ function, which is defined in the text below, satisfies certain properties (e.g., that $\left.\alpha_{h} \beta_{h}^{\prime}(e)=-\alpha_{l} \beta_{l}^{\prime}(e)\right)$. Our assumptions about the signaling technology ensure that these
} 


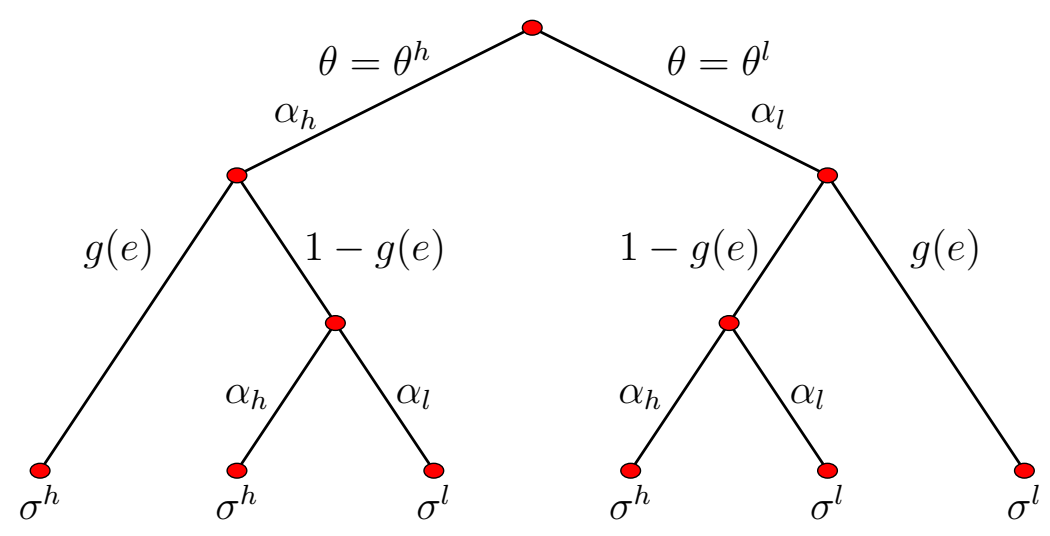

Figure 1: The signal technology. Nature draws state $\theta^{i}$ with probability $\alpha_{i}$. The signal indicates the true state with probability $g(e)$ and is drawn from the prior with probability $1-g(e)$.

Let $\beta_{i}(e)$ denote the consumer's expected accident probability, given a signal $\sigma^{i}$ and an effort level $e$. Formally, $\beta_{i}(e) \equiv \sum_{j \in\{l, h\}} \operatorname{Pr}\left[\theta=\theta^{j} \mid \sigma=\sigma^{i}\right] \theta^{j}$. Similarly, let $\beta$ denote the consumer's expected accident probability, given only the prior: $\beta \equiv \sum_{i=l, h} \alpha_{i} \theta^{i}$. By using Bayes' rule and the above assumptions about the signal technology, one can easily verify that

$$
\beta_{h}(e)=\beta+\alpha_{l}\left(\theta^{h}-\theta^{l}\right) g(e) .
$$

It is clear from the above expression that $\beta_{h}(e)$ inherits the curvature assumptions that we made about $g(e)$. In particular, $\beta_{h}^{\prime}(e)>0$ and $\beta_{h}^{\prime \prime}(e) \leq 0$. One can similarly check that $\beta_{l}^{\prime}(e)<0$ and $\beta_{l}^{\prime \prime}(e) \geq 0$. Furthermore, $\beta_{h}(0)=\beta_{l}(0)=\beta{ }^{8}$ The fact that the unconditional probability of receiving a high signal equals $\alpha_{h}$ at every effort level implies, together with Bayes' rule, that

$$
\sum_{i \in\{l, h\}} \alpha_{i} \beta_{i}(e)=\beta \quad \text { for all } e \geq 0
$$

By differentiating both sides of the identity in (1) with respect to $e$, one obtains $\alpha_{h} \beta_{h}^{\prime}(e)=-\alpha_{l} \beta_{l}^{\prime}(e)$, which we will make use of in the subsequent analysis.

Exerting positive effort leads to a disutility $c(e)$ for the consumer, which enters additively in his payoff. ${ }^{9}$ The cost function $c$ is strictly increasing, strictly convex,

hold. Second, these properties of the $\beta_{i}(e)$ function are sufficient for proving our results. We have no particular reason to believe that they are also necessary. We conjecture that our main results hold more generally.

${ }^{8}$ For an example of our signaling technology, consider $g(e)=1-(1+e)^{-1}$. This gives us $\beta_{h}(e)=$ $\sum_{i=l, h} \alpha_{i} \theta^{i}+\alpha_{l}\left(\theta^{h}-\theta^{l}\right)\left[1-(1+e)^{-1}\right]$. Differentiating this expression yields $\beta_{h}^{\prime}(e)=\alpha_{l}\left(\theta^{h}-\theta^{l}\right)(1+$ $e)^{-2}>0$ and $\beta_{h}^{\prime \prime}(e)=-2 \alpha_{l}\left(\theta^{h}-\theta^{l}\right)(1+e)^{-3}<0$.

${ }^{9}$ In the supplementary material to this paper, we explore a setup where the costs of effort are monetary and enter, therefore, in the argument of the utility function; see the discussion in section 7 . 
twice continuously differentiable and satisfies $c(0)=c^{\prime}(0)=0$. A consumer's expected utility after exerting effort $e$, receiving signal $\sigma^{i}$ and buying the insurance contract $(p, R)$ is therefore

$$
U=\beta_{i}(e) u(w-p-D+R)+\left[1-\beta_{i}(e)\right] u(w-p)-c(e) .
$$

The solution concept we employ is weak perfect Bayesian equilibrium. We will solve the game by backward induction, starting with the consumer's contract choice. Before doing that, however, it is useful to here have a preliminary look at the insurer's problem at stage 2 of the game.

\subsection{A Preliminary Look at the Insurer's Problem}

When stating the insurer's problem, we will (following the standard approach) treat the consumer's effort level as if it were chosen by the insurer, but subject to constraints that ensure that the effort level coincides with the consumer's actually preferred choice. Moreover, because of the binary nature of the signal, we can without loss of generality rule out menus that consist of more than two contracts. ${ }^{10}$ Hence, suppose there are two contracts, $l$ and $h$, which are targeted at the low-signal type and the high-signal type, respectively.

The insurer's problem is to choose a recommended effort level $e$ and a premiumindemnity pair $\left(p_{i}, R_{i}\right)$, to solve

$$
\max _{e,\left(p_{l}, R_{l}\right),\left(p_{h}, R_{h}\right)} \sum_{i \in\{l, h\}} \alpha_{i}\left[p_{i}-\beta_{i}(e) R_{i}\right]
$$

subject to the following constraints. First, exactly as in the standard screening problem with two types, there are two interim incentive compatibility constraints $\left(\mathrm{IC}_{1}\right.$ and $\left.\mathrm{IC}_{\mathrm{h}}\right)$ and two interim individual rationality constraints $\left(\mathrm{IR}_{\mathrm{l}}\right.$ and $\left.\mathrm{IR}_{\mathrm{h}}\right)$. In addition there is an information gathering constraint (IG), which ensures that the consumer chooses the recommended effort level $e$.

The (IG) constraint is the key to the analysis: It is responsible for our novel results, and it also contributes to making parts of the analysis somewhat difficult. If the cost of information gathering were either negligible or very large, then the (IG) constraint would be trivial. (We can obtain these special cases of the model by replacing the cost function $c(e)$ by $\gamma c(e)$, and then let $\gamma \rightarrow 0$ and $\gamma \rightarrow \infty$, respectively.) Indeed, one can

\footnotetext{
${ }^{10}$ Any behavior on the part of the consumer that the insurer can induce with such a menu can just as well be induced with the help of only one or (at most) two contracts. This is a standard result and we will not prove it here. However, the interested reader can find a formal proof in the supplementary material.
} 
show that if the cost becomes negligible $(\gamma \rightarrow 0)$, then the equilibrium contract menu induces a strictly positive effort level and it converges to the Stiglitz menu.Similarly, if the cost becomes very large $(\gamma \rightarrow \infty)$, then the equilibrium contract menu induces a zero effort level and all offered contracts involve full coverage (as then there is no informational asymmetry). ${ }^{11}$

When the cost is neither negligible nor very large, the main difficulty in the analysis lies in computing the (IG) constraint. There are two complications in doing this. First, the consumer's expected utility (at stage 3 where he chooses his effort) is, as a function of $e$, not quasiconcave. This issue is discussed in section 4. Second, we must consider the possibility that the consumer makes a "double deviation." That is, the consumer may first (at stage 3) choose an effort level that is different from the recommended one and then (at stage 4) misrepresent his signal. In section 5, we thus decompose the (IG) constraint into one on-path constraint and three off-path constraints. The three latter constraints ensure that the consumer does not want to: (i) deviate to $e^{\prime}>e$ and buy insurance only upon receiving a high signal, which is constraint (EH) in section 5; (ii) deviate to $e^{\prime}=0$ and buy the high-coverage contract, which is constraint $\left(\mathrm{IG}_{\mathrm{h}}\right)$; and (iii) deviate to $e^{\prime}=0$ and buy the low-coverage contract, which is constraint $\left(\mathrm{IG}_{1}\right)$.

We will in section 5 (in particular, in lemma 1) show that the constraints that bind in equilibrium are $(\mathrm{EH})$ and $\left(\mathrm{IG}_{\mathrm{l}}\right)$. Before being able to do that, however, we must study the consumer's optimal behavior at stages 4 and 3, and we must state the constraints more carefully. We begin in the next section by considering the consumer's contract choice at stage 4 .

\section{Contract choice}

At stage 2 of the game, the insurer chooses a menu of contracts, which the consumer takes as given when making his contract choice. As already explained, we can focus on menus with at most two contracts. We will also, without loss of generality, assume that neither one of the two contracts dominates the other: If one of the contracts has a higher indemnity, then it must also have a higher premium (if not, the second contract would never be chosen by the consumer and the insurer could just as well exclude it from the menu).

When making his contract choice, the consumer thus has up to three options (up to two contracts in the menu and the outside option of no insurance). Suppose there are indeed two contracts in the menu and that these are distinct from each other and indexed by $j \in\{l, h\}$. In addition, refer to the option of not purchasing any insurance

\footnotetext{
${ }^{11}$ We will state these results more carefully in proposition 2.
} 
as "contract 0 " and accordingly write $p_{0}=R_{0}=0$. Let $\underline{u}_{j}$ denote the consumer's utility if having chosen contract $j$ and then having an accident. Similarly, let $\bar{u}_{j}$ denote the consumer's utility if having chosen contract $j$ and then not having an accident. Formally, $\underline{u}_{j} \equiv u\left(w-D-p_{j}+R_{j}\right)$ and $\bar{u}_{j} \equiv u\left(w-p_{j}\right)$ for $j \in\{0, l, h\}$.

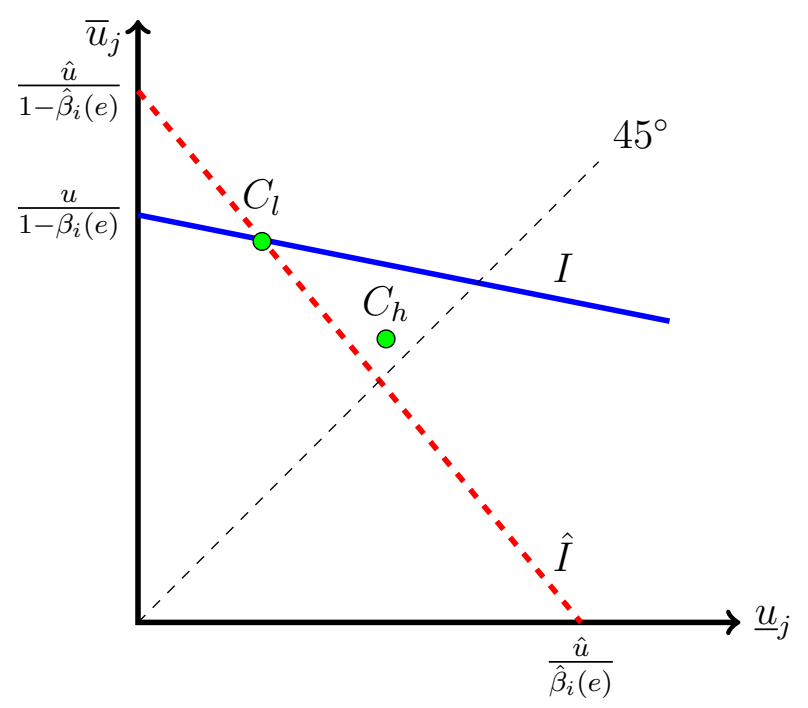

Figure 2: The consumer's contract choice. The higher is the consumer's expected accident risk $\beta_{i}(e)$, the greater is his tendency to choose an option with relatively high coverage.

What will determine the consumer's choice between contracts $0, l$ and $h$ ? To answer this question we will make use of figure 2. This figure shows contracts $l$ and $h$ as points $C_{l}$ and $C_{h}$ in the $\left(\underline{u}_{j}, \bar{u}_{j}\right)$-space. Note that $C_{h}$ is located southeast of $C_{l}$. This amounts to an assumption that, in line with our mnemonic notation, contract $h$ involves a relatively high coverage and contract $l$ involves a relatively low coverage $\left(\bar{u}_{h}<\bar{u}_{l}\right.$ and $\left.\underline{u}_{h}>\underline{u}_{l}\right)$. We now make the following claim: The higher is the consumer's expected accident risk $\beta_{i}(e)$, the greater is his tendency to choose an option with relatively high coverage. To show that this is true, we have in the figure drawn an indifference curve for the consumer (as a solid straight line), denoted by $I$, that goes through point $C_{l}$. Since $C_{h}$ is located southwest of $I$, for these preferences the consumer prefers contract $l$. The equation for the indifference curve can be written as

$$
\bar{u}_{j}=\frac{u}{1-\beta_{i}(e)}-\frac{\beta_{i}(e)}{1-\beta_{i}(e)} \underline{u}_{j}
$$

where $u$ is the fixed utility level associated with this indifference curve. This means that an indifference curve associated with a larger value of $\beta_{i}(e)$ must be steeper. Such an indifference curve, denoted by $\hat{I}$, is also shown in figure 2 (as a dashed straight line). 
Since $C_{h}$ is located northeast of $\hat{I}$ while $C_{l}$ is located exactly at $\hat{I}$, for these preferences the consumer prefers contract $h$. More generally, it is clear that if there are two contracts in the menu and neither one dominates the other, then for $\beta_{i}(e)$ sufficiently close to zero the consumer prefers the low-coverage contract and for $\beta_{i}(e)$ sufficiently close to one he prefers the high-coverage contract. We can conclude that, if we let $\beta_{i}(e)$ gradually increase (and assume that its initial value is sufficiently low), the preferred contract of a consumer with signal $i$ will move, in turn, from contract 0 to contract $l$ to contract $h$.

\section{Effort choice}

We can write the consumer's expected utility, at the point in time when he is about to choose the effort level $e$, as

$$
U(e)=\sum_{i \in\{l, h\}} \alpha_{i}\left[\beta_{i}(e) \underline{u}_{m}+\left(1-\beta_{i}(e)\right) \bar{u}_{m}\right]-c(e)
$$

where $\underline{u}_{m}$ and $\bar{u}_{m}$ are the utility levels associated with the contract $m \in\{0, l, h\}$ that the consumer optimally chooses after having observed the signal $i$. As the effort level $e$ varies, this optimally chosen contract may change, since $\beta_{l}(e)$ and $\beta_{h}(e)$ both depend on $e$. The function $U(e)$ is therefore not necessarily everywhere differentiable with respect to $e$, as it may have a kink at a point where the consumer, for a given signal, prefers to move from one contract to another (although $U(e)$ is continuous for all $e \geq 0$ ). However, the analysis of the previous section - and the monotonicity of $\beta_{h}(e)$ and $\beta_{l}(e)$ in effort-imply that there can only be two such kinks. Everywhere else the expression is indeed differentiable. So if we (for example) suppose that contract $i \in\{l, h\}$ is the consumer's optimal contract when having observed signal $i$, then we can calculate

$$
\begin{aligned}
U^{\prime}(e) & =\sum_{i \in\{l, h\}} \alpha_{i}\left[\beta_{i}^{\prime}(e) \underline{u}_{i}-\beta_{i}^{\prime}(e) \bar{u}_{i}\right]-c^{\prime}(e) \\
& =\alpha_{h} \beta_{h}^{\prime}(e)\left[\left(\bar{u}_{l}-\underline{u}_{l}\right)-\left(\bar{u}_{h}-\underline{u}_{h}\right)\right]-c^{\prime}(e)
\end{aligned}
$$

where the second equality follows from $\alpha_{h} \beta_{h}^{\prime}(e)=-\alpha_{l} \beta_{l}^{\prime}(e)$.

Thus an increase in the consumer's effort has potentially two effects on his utility. First, it always increases the information gathering cost $c(e)$. This effect is negative and it is captured by the last term in (4). Second, if the consumer chooses different contracts after having observed the two possible signals, then a larger $e$ increases the probability of a correct contract choice. This effect on the consumer's utility is positive and it is captured by the first term in (4) (note that we always have $\bar{u}_{l}-\underline{u}_{l} \geq \bar{u}_{h}-\underline{u}_{h}$, with the inequality being strict if the contracts are different). 
It follows that if the consumer for some interval of effort levels chooses the same contract regardless of the signal, then $U^{\prime}(e)=-c^{\prime}(e)<0$. For example, if the consumer, given his prior (i.e., with zero effort), prefers one contract strictly over the others, then $U(e)$ is strictly decreasing in the effort level for $e$ small enough. The function $U(e)$ is also strictly concave in that interval (since $c^{\prime \prime}(e)>0$ ). Moreover, if the consumer for some interval of effort levels chooses different contracts for different signals, then his expected utility is possibly increasing in $e$. The implication of these observations is that, despite $\beta_{h}^{\prime \prime} \leq 0$ and the fact that the cost function is strictly convex, the expected utility function $U(e)$ is not guaranteed to be quasiconcave.

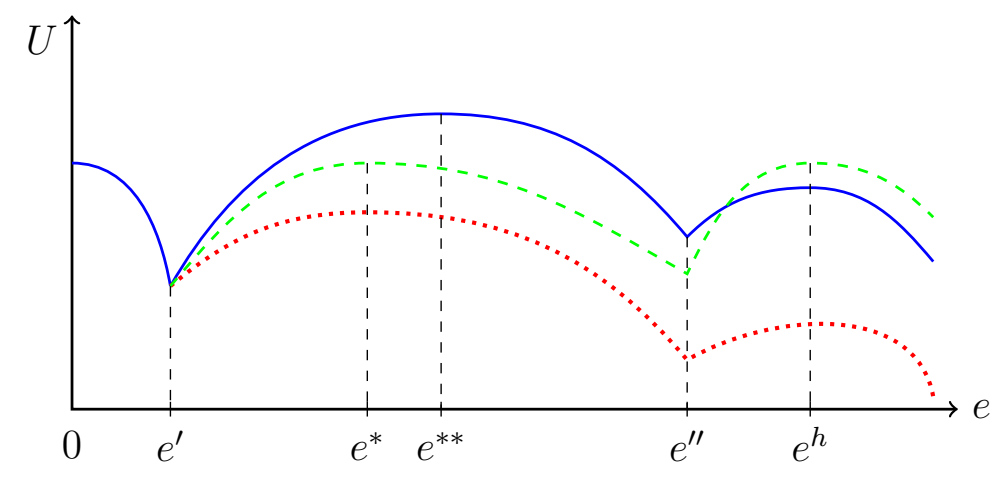

Figure 3: Utility as function of effort given optimal contract choice.

We illustrate the lack of quasiconcavity with the help of figure 3. Suppose, as before, that the insurer has offered a menu with two distinct contracts, $l$ and $h$. Also suppose that for $e=0$ the consumer strictly prefers contract $l$ to contracts 0 and $h$. Then $U(e)$ must be strictly decreasing at $e=0$ : The consumer prefers contract $l$ irrespective of the signal also after a small increase in effort. Hence, the additional information has no benefit, only a cost. As we gradually increase $e$, starting from zero, $\beta_{h}(e)$ becomes larger and $\beta_{l}(e)$ becomes smaller. Therefore, at some point (say, at $e^{\prime}>0$ ) the consumer will be indifferent between contracts $l$ and $h$ when he receives a high signal, and at some point (say, at $e^{\prime \prime}>0$ ) the consumer will be indifferent between contracts 0 and $l$ when receiving a low signal (see the solid curve). In figure 3, we have $e^{\prime}<e^{\prime \prime}$ (the reverse relationship is possible in principle but is not relevant in the profit maximizing contract menu). For effort levels immediately above $e^{\prime}, U(e)$ could be increasing if $c^{\prime}\left(e^{\prime}\right)$ is not too high. Eventually, however, $U(e)$ will decrease again, because the cost effect of increasing $e$ becomes larger $\left(c^{\prime \prime}>0\right)$ while the information effect becomes smaller $\left(\beta_{h}^{\prime \prime} \leq 0\right)$. At $e^{\prime \prime}$, the consumer with a low signal decides to remain uninsured instead of buying contract l. Again, $U(e)$ may be increasing for effort levels immediately above $e^{\prime \prime}$, but eventually it will decrease again. If the utility function is the solid curve in figure 3 , optimal effort 
is $e^{* *}>0$. In contrast, if the utility function is the dotted curve (from $e^{\prime}$ onwards), the optimal effort is zero. Similarly, if the utility function is the dashed curve (from $e^{\prime}$ onwards), zero effort, the effort $e^{*}>0$ and the effort $e^{h}>e^{*}$ are all three optimal.

Hence, there can be several interior local maxima as well as a local maximum at the boundary, $e=0$. The convexity of the cost function and $\beta_{h}^{\prime \prime} \leq 0$ ensure that $U(e)$ is strictly concave on $\left[0, e^{\prime}\right]$ and on $\left[e^{\prime}, e^{\prime \prime}\right]$ as well as on $\left[e^{\prime \prime}, \infty\right)$. Therefore, $U(e)$ can have up to three local maxima if two contracts are offered. These model features also imply that, for a given contract choice strategy, the optimal effort choice will be pinned down by a first-order condition. In particular, suppose the insurer wants to induce an outcome with $e>0$ and where the consumer purchases contract $h$ if he gets a high signal and contract $l$ if he receives a low signal. Then the consumer's optimal effort is the unique solution to the first-order condition

$$
\alpha_{h} \beta_{h}^{\prime}(e)\left[\left(\bar{u}_{l}-\underline{u}_{l}\right)-\left(\bar{u}_{h}-\underline{u}_{h}\right)\right]-c^{\prime}(e)=0 .
$$

A similar condition (with the subindex $l$ replaced by 0) would characterize the consumer's optimal effort $e^{h}$ if he wanted to buy contract $h$ when receiving a high signal and to remain uninsured when receiving a low signal.

\section{Contract design}

We now turn to the profit maximization problem of the monopolist insurer. Depending on what consumer behavior the insurer optimally induces, the solution to this problem will belong to one of the following three categories:

1. Pooling. The consumer does not gather information $(e=0)$ but does purchase an insurance contract (independently of any signal as with zero effort there is no informative signal).

2. Exclusion. The consumer gathers information $(e>0)$ and purchases an insurance only if receiving the signal $\sigma^{h}$ (hence the low-type consumer remains uninsured).

3. Separation. The consumer gathers information $(e>0)$ and purchases insurance contract $h$ (i.e., the one with high coverage) if observing the signal $\sigma^{h}$ and contract $l$ (i.e., the one with low coverage) if receiving the signal $\sigma^{l}$.

In insurance models without information acquisition, pooling equilibria do not exist. On the other hand, inducing no effort is always optimal in the procurement model of Crémer and Khalil (1992). The reason for this is that the agent in Crémer and Khalil (1992) will learn his type before he has to choose a contract from the menu, even if 
he does not gather information. The information gathering is therefore only relevant for his ex ante participation decision. Hence, providing the agent with an option to reject any contract ex post is enough to discourage information acquisition. In fact, this is optimal because it allows the principal to extract some of the effort costs that are saved. Discouraging information acquisition is much harder in our model because no information acquisition implies not only no information in the participation decision but also no information in the contract choice. Therefore, adding an outside option to the menu cannot prevent information acquisition. The principal has to completely change the contract menu if he wants to implement zero effort. We will indeed show that-depending on parameter values - each equilibrium type can be optimal in our model.

\subsection{Constraints in COntract Design}

In this subsection, we explain the constraints that appear in the profit maximization problem of the insurer. We also show which of these are binding at the optimum. In the text below we will, to begin with, discuss the constraints that are relevant if the insurer's optimal menu involves separation. After having done this, however, we will show that this setup includes the possibilities of pooling and exclusion as special cases. Hence, we will be able to deal with all possible contract designs within one single formulation of the insurer's problem.

Thus suppose that the insurer wants to induce separation. The insurer's problem is then to maximize his expected profits subject to altogether nine constraints. Four of the constraints concern the consumer's behavior at the interim stage where he has observed the signal; these are identical to the constraints in standard formulations of the screening problem, namely, two individual rationality constraints and two incentive compatibility constraints (one of each for each type). As in the standard screening problem, it is straightforward to show that only the low type's individual rationality constraint and the high type's incentive compatibility constraint can be relevant. These constraints read:

$$
\begin{gathered}
\beta_{l}(e) \underline{u}_{l}+\left(1-\beta_{l}(e)\right) \bar{u}_{l} \geq \beta_{l}(e) \underline{u}_{0}+\left(1-\beta_{l}(e)\right) \bar{u}_{0}, \\
\beta_{h}(e) \underline{u}_{h}+\left(1-\beta_{h}(e)\right) \bar{u}_{h} \geq \beta_{h}(e) \underline{u}_{l}+\left(1-\beta_{h}(e)\right) \bar{u}_{l} .
\end{gathered}
$$

The remaining five constraints concern the consumer's behavior at the ex ante stage, prior to the observation of the signal. First, the consumer must find the effort level $e$ optimal (given that he chooses contract $h(l)$ when receiving a high (low) signal). In particular, the first-order condition in (5) must be satisfied. This condition is necessary 
and sufficient for $e$ to maximize the consumer's expected utility, given that he chooses contract $h$ after a high signal and contract $l$ after a low signal.

Second, we must consider deviations where the consumer deviates in both effort and contract choice. We start by considering deviations to an effort level $e^{h}>e$ while adjusting the contract choice optimally. Following the results of section 3 , it is then still optimal to buy contract $h$ in case of a high signal (as $\beta_{h}\left(e^{h}\right)>\beta_{h}(e)$ and $\left(\mathrm{IC}_{\mathrm{h}}\right)$ holds). Similarly, contract $l$ is preferred to contract $h$ when receiving a low signal (as $\left.\beta_{l}\left(e^{h}\right)<\beta_{l}(e)\right)$. However, it might be optimal to remain uninsured when receiving a low signal instead of buying contract $l$. Such a deviation is not profitable if the following constraint is satisfied:

$$
\begin{aligned}
& \sum_{i \in\{l, h\}} \alpha_{i}\left[\beta_{i}(e) \underline{u}_{i}+\left(1-\beta_{i}(e)\right) \bar{u}_{i}\right]-c(e) \\
& \quad \geq \alpha_{h}\left[\beta_{h}\left(e^{h}\right) \underline{u}_{h}+\left(1-\beta_{h}\left(e^{h}\right)\right) \bar{u}_{h}\right]+\alpha_{l}\left[\beta_{l}\left(e^{h}\right) \underline{u}_{0}+\left(1-\beta_{l}\left(e^{h}\right)\right) \bar{u}_{0}\right]-c\left(e^{h}\right),
\end{aligned}
$$

where the effort level $e^{h}$ satisfies the following first-order condition:

$$
c^{\prime}\left(e^{h}\right)=\alpha_{h} \beta_{h}^{\prime}\left(e^{h}\right)\left[\left(\bar{u}_{0}-\underline{u}_{0}\right)-\left(\bar{u}_{h}-\underline{u}_{h}\right)\right] .
$$

Because of $\beta_{h}^{\prime \prime} \leq 0$ and $c^{\prime \prime}>0$, this first-order condition is necessary and sufficient for $e^{h}$ to maximize the consumer's expected utility, given that he chooses contract $h$ after a high signal and contract 0 after a low signal.

Next, we consider deviations where the consumer chooses an effort level $e^{l}<e$. Following the results of section 3 , contract $l$ is still preferred to remaining uninsured if the signal is low (as $\beta_{l}\left(e^{l}\right)>\beta_{l}(e)$ and $\left(\mathrm{IR}_{1}\right)$ holds). A low-signal consumer might, however, prefer contract $h$ to contract $l$ for $e^{l}<e$. In this case, the consumer buys contract $h$ both after a high and a low signal. Obviously, the optimal effort level $e^{l}$ in such a deviation is zero, which means the relevant constraint is

$$
\sum_{i \in\{l, h\}} \alpha_{i}\left[\beta_{i}(e) \underline{u}_{i}+\left(1-\beta_{i}(e)\right) \bar{u}_{i}\right]-c(e) \geq \beta \underline{u}_{h}+(1-\beta) \bar{u}_{h} .
$$

We call this constraint "information gathering constraint high," as the threat of the consumer is to refrain from gathering information while buying the high-coverage contract.

When considering effort levels $e^{l}<e$, we also have to consider the possibility that a high-signal consumer prefers contract $l$ to contract $h$. In such a deviation, the consumer buys contract $l$ after both signals and the optimal effort level in this deviation is again 0 . The constraint corresponding to this deviation ("information gathering low") is therefore

$$
\sum_{i \in\{l, h\}} \alpha_{i}\left[\beta_{i}(e) \underline{u}_{i}+\left(1-\beta_{i}(e)\right) \bar{u}_{i}\right]-c(e) \geq \beta \underline{u}_{l}+(1-\beta) \bar{u}_{l} .
$$


Note that we do not have to consider the possibility where a high-signal consumer remains uninsured after $e^{l}<e:^{12}$ As we established that a low-signal consumer prefers contract $l$ to remaining uninsured and as $\beta_{h}\left(e^{l}\right) \geq \beta_{l}\left(e^{l}\right)$, a high-signal consumer always prefers contract $l$ to remaining uninsured; see section 3 .

The constraints that we have discussed also cover the exclusion and pooling cases. To see this, first suppose that the insurer wants to induce pooling. We can view pooling as making contracts $l$ and $h$ identical $\left(\bar{u}_{l}=\bar{u}_{h}\right.$ and $\left.\underline{u}_{l}=\underline{u}_{h}\right)$ and providing the consumer with incentives to choose $e=0$. The same interim constraints as above are required, although several of them are trivially satisfied when the two contracts are the same. The constraint (EH) ensures then that the consumer has no incentive to gather information: It states that the consumer does not want to choose the effort level $e^{h}>e=0$ and then reject the single contract in the menu when observing the low signal (this is the only way in which the consumer would be able and potentially willing to deviate to a positive effort level). The constraint $\left(\mathrm{IR}_{1}\right)$ ensures that the consumer is willing to participate. The remaining constraints - namely, $\left(\mathrm{IG}_{\mathrm{l}}\right),\left(\mathrm{IG}_{\mathrm{h}}\right),\left(\mathrm{IC}_{\mathrm{h}}\right)$, and the first-order condition in (5) - will be trivially satisfied under pooling (recall our assumption that $c^{\prime}(0)=0$ ).

The case with exclusion is similar. Exclusion can be viewed as offering a contract $l$ that is identical to contract $0\left(\bar{u}_{l}=\bar{u}_{0}\right.$ and $\left.\underline{u}_{l}=\underline{u}_{0}\right)$. In this case, the consumer optimally chooses $e=e^{h}>0$ as (5) and (6) coincide. The constraint $\left(\mathrm{IG}_{1}\right)$ becomes an "ex ante individual rationality constraint" in this case. The constraint $\left(\mathrm{IC}_{\mathrm{h}}\right)$ is effectively the high type's (interim) individual rationality constraint, and $\left(\mathrm{IR}_{1}\right)$ and $(\mathrm{EH})$ are trivially satisfied.

When formulating the insurer's profit maximization problem we will not have to consider all the constraints discussed above. The following lemma tells us that $\left(\mathrm{IG}_{1}\right)$ and $(\mathrm{EH})$ are binding in equilibrium while all other constraints that were stated as inequalities can be neglected. (The optimal effort conditions (5) and (6) are obviously also binding.) Graphically, this means that the three local maxima in figure 3 yield the same expected utility under the optimal contract menu (as shown by the dashed curve in that figure)..$^{13}$

Lemma 1. Constraints $\left(I C_{h}\right)$ and $\left(I R_{l}\right)$ are implied by $(E H)$ and $\left(I G_{l}\right)$. In equilibrium, $(E H)$ and $\left(I G_{l}\right)$ bind while $\left(I G_{h}\right)$ is slack.

Lemma 1 is not only technically important for solving the contract design problem

\footnotetext{
${ }^{12}$ In particular, this holds for $e^{l}=0$, which implies that we do not have to track an "ex ante individual rationality constraint" (EAIR) explicitly: (EAIR) is implied by $\left(\mathrm{IR}_{1}\right)$ and $\left(\mathrm{IG}_{1}\right)$.

${ }^{13}$ The result that the information gathering constraints imply truthtelling (i.e., the IC constraints) is due to the binary signal technology. That is, if more signals were possible, some incentive compatibility constraints would bind.
} 
but has also a straightforward economic implication. Consider the cases of separation and exclusion (i.e., the ones where the consumer chooses a positive effort level). Since $\left(\mathrm{IG}_{\mathrm{l}}\right)$ is binding the consumer will be indifferent between information acquisition and no information acquisition when facing the optimal menu. Doherty and Thistle (1996) refer to the utility difference between acquiring information (and choosing the best contract given the acquired information) and not acquiring information (and choosing the best contract given the prior) as the value of information to the agent. To indicate that we refer to this utility difference given the optimal menu, we prefer to call this concept the equilibrium value of information. We can conclude the following:

Corollary 1. The equilibrium value of information to the agent is zero.

Despite the corollary, effort can be positive in equilibrium. The corollary only states that, in equilibrium, the consumer will be indifferent between the optimal positive effort and no effort (this also holds in the pooling case where optimal effort is zero because (6) binds). In this respect, our model differs from other models of endogenous information acquisition (e.g., Crémer et al. (1998), Szalay (2009), and Doherty and Thistle (1996)), in which consumers can have strict preferences over effort in equilibrium. The reason why our result is different is that in our model the consumer's effort choice problem is (i) continuous and (ii) non-quasiconcave (in particular, the consumer's effort choice problem has several local maxima and one of those is the boundary solution $e=0$ ).

\subsection{Profit MAXimization PROGRAM AND Distortion RESUlts}

We now turn to the formulation of the insurer's profit maximization problem. As is often the case in the formal insurance literature, it will be more convenient to work with the inverse of the utility function than with this function directly. We let $h(u)$ denote this inverse (i.e., $h \equiv u^{-1}$ ) and note that $h^{\prime}(u)>0$ and $h^{\prime \prime}(u)>0$. By lemma 1 , the optimal menu of contracts solves the following program: ${ }^{14}$

$$
\max _{\bar{u}_{l}, \underline{u}_{l}, \bar{u}_{h}, \underline{u}_{h}, e, e^{h}}\left\{w-\beta D-\sum_{i \in\{l, h\}} \alpha_{i}\left[\beta_{i}(e) h\left(\underline{u}_{i}\right)+\left(1-\beta_{i}(e)\right) h\left(\bar{u}_{i}\right)\right]\right\}
$$

subject to the binding $\left(\mathrm{IG}_{\mathrm{l}}\right)$ and $(\mathrm{EH})$ constraints, equalities (5) and (6), and $e^{h} \geq e \geq 0$.

The four first constraints - the binding $\left(\mathrm{IG}_{1}\right)$ and $(\mathrm{EH})$ and equalities (5) and (6) are all linear in the consumer's ex post utility levels. It is therefore straightforward to solve the four constraints for the four utility levels as functions of $e$ and $e^{h}$. Doing that yields the four functions $\underline{u}_{i}\left(e, e^{h}\right)$ and $\bar{u}_{i}\left(e, e^{h}\right)$, for $i=l, h$. These functions can

\footnotetext{
${ }^{14}$ The objective function in (7) is an equivalent way of writing the objective in (2), i.e., the insurer's expected profits.
} 
be plugged into the objective function (7), thus giving us the following reduced-form optimization problem with only two choice variables:

$$
\max _{e, e^{h}}\left\{-\sum_{i \in\{l, h\}} \alpha_{i}\left[\beta_{i}(e) h\left(\underline{u}_{i}\left(e, e^{h}\right)\right)+\left(1-\beta_{i}(e)\right) h\left(\bar{u}_{i}\left(e, e^{h}\right)\right)\right]\right\}, \quad \text { s.t: } e^{h} \geq e \geq 0,
$$

where we for convenience have omitted the additive constants. If the solution to the problem is such that the constraint $e=0$ binds, then that means that the equilibrium is pooling. If the solution is such that $e=e^{h}$, then we have an equilibrium with exclusion.

To gain some insight into the nature of this maximization problem, consider the derivative of the objective with respect to $e$, evaluated at $e=0$ (this expression can easily be derived from the first-order condition (15), stated in the Appendix):

$$
\frac{\partial \pi\left(0, e^{h}\right)}{\partial e}=-\alpha_{l} \beta(1-\beta)\left[h^{\prime}\left(\bar{u}_{l}\right)-h^{\prime}\left(\underline{u}_{l}\right)\right] \frac{c^{\prime \prime}(0)}{\alpha_{h} \beta_{h}^{\prime}(0)} \leq 0 .
$$

That is, evaluated at $e=0$, the derivative is always non-positive. Indeed, if $c^{\prime \prime}(0)>$ 0 , then the derivative is strictly negative and therefore $e=0$ must thus be a local maximum. However, as we have already noted, the optimization program above is not quasiconcave and therefore the globally profit maximizing menu of contracts can lead to positive effort.

The lack of quasiconcavity of the maximization problem implies that the first-order conditions allow for multiple solutions. This is true even for simple functional formsfor example, for a linear signaling technology and a quadratic cost function. However, as the insurer's problem can be written as the problem of maximizing a continuous function over a compact and convex set, the problem is easy to solve numerically. ${ }^{15}$ Table 1 shows the solution for a specific example (see Appendix B for more information). ${ }^{16}$ As the right-most column shows, as the cost parameter gradually becomes larger, the optimal contract goes from involving exclusion, to separation, to pooling which gives us the following result.

Result 1. There exist parameter values such that each equilibrium type-pooling, exclusion, separation-exists.

\footnotetext{
${ }^{15}$ Compactness of the domain is not apparent from (8). However, it is easy to bound $e^{h}$ from above by some $\bar{e}$ : For example, $\bar{e}$ defined by $c(\bar{e})=u(w-\beta D)-\left(\beta \underline{u}_{0}+(1-\beta) \bar{u}_{0}\right)$ is such an upper bound, as the right-hand side is an upper bound on the benefit a consumer can get from insurance.

${ }^{16}$ The example uses the cost function $c(e)=\gamma e^{4}$. Also with a quadratic cost function equilibria with positive equilibrium effort exist. However, we did not find parameter values where only varying $\gamma$ allowed us to move through all three equilibrium types.
} 


\begin{tabular}{l||c|c|c|c|c|c|c|c|c} 
& $\bar{u}_{h}$ & $\underline{u}_{h}$ & $\bar{u}_{l}$ & $\underline{u}_{l}$ & $e$ & $e^{h}$ & $\pi$ & $E U$ & equilibrium \\
\hline$\gamma=0.05$ & 1.6929 & 1.6439 & 2 & 1 & 0.5311 & 0.5311 & 0.1408 & 1.695 & exclusion \\
$\gamma=0.1$ & 1.6946 & 1.6512 & 2 & 1 & 0.4223 & 0.4223 & 0.1424 & 1.695 & exclusion \\
$\gamma=0.2$ & 1.7052 & 1.6576 & 1.9646 & 1.0954 & 0.3186 & 0.3347 & 0.1442 & 1.6995 & separating \\
$\gamma=0.5$ & 1.7316 & 1.6415 & 1.8556 & 1.3671 & 0.1844 & 0.2429 & 0.1546 & 1.7066 & separating \\
$\gamma=0.58$ & 1.7334 & 1.6398 & 1.8322 & 1.3985 & 0.1681 & 0.2309 & 0.1567 & 1.7068 & separating \\
$\gamma=0.6$ & 1.7322 & 1.6425 & 1.8411 & 1.4007 & 0.1663 & 0.2286 & 0.1571 & 1.7067 & separating \\
$\gamma=0.7$ & 1.7352 & 1.6378 & 1.8263 & 1.4348 & 0.1490 & 0.2165 & 0.1593 & 1.7069 & separating \\
$\gamma=1.0$ & 1.7559 & 1.5970 & 1.7559 & 1.5970 & 0 & 0.1878 & 0.1643 & 1.7074 & pooling \\
$\gamma=1.3$ & 1.7512 & 1.6050 & 1.7512 & 1.6050 & 0 & 0.1729 & 0.1679 & 1.7067 & pooling
\end{tabular}

Table 1: Optimal contracts, given the utility function $u(x)=\sqrt{x}$ and the cost function $c(e)=\gamma e^{4}$. Moreover, $w=4, D=3, \theta^{h}=0.35, \theta^{l}=0.2, \alpha_{h}=0.7$, and $g(e)=$ $\min \{e, 1\}$. The numbers are rounded on the fourth digit.

In proposition 1 below, we state one of our our main results, which concerns the allocative efficiency of the equilibrium contracts. The result says that all equilibrium contracts must involve underinsurance. This result stands in sharp contrast to the usual "no distortion at the top" property that holds in standard insurance models with exogenously given types.

Proposition 1. All insurance contracts in the equilibrium menu have less than full coverage (i.e., $\underline{u}_{l}<\bar{u}_{l}$ and $\underline{u}_{h}<\bar{u}_{h}$ ).

Recall that in the standard model with exogenously given types, the low-risk type is offered a contract with partial coverage. This distortion allows the insurer to charge the high-risk type a higher premium: Since the high-risk type values insurance highly, reducing the coverage of the low-risk type's contract makes this contract unattractive for the high-risk type. Technically speaking, the distortion relaxes the binding incentive compatibility constraint of the high-risk type. The high-risk type's contract is not distorted because the low-risk type's incentive compatibility constraint is slack and therefore no binding constraint could be relaxed by distorting this contract. In our model with endogenous information acquisition, both incentive compatibility constraints are slack (see lemma 1). Hence, the standard reasons for (non-) distortion do not apply. The binding (EH) constraint, however, can be relaxed by distorting the highrisk type's contract: The deviation associated with (EH) involves exerting more effort than in equilibrium $\left(e^{h}>e\right)$ and then to continue to buy the high-coverage contract in case of a high signal (and otherwise choose the outside option). A consumer that receives a high signal after exerting the high effort $e^{h}$ has a particularly high risk (i.e., $\left.\beta_{h}\left(e^{h}\right)>\beta_{h}(e)\right)$ and therefore values insurance particularly highly. Distorting the highsignal type's coverage downwards will therefore hurt a high-signal type in the deviation 
more than a high-signal type that does not deviate. Consequently, the binding (EH) constraint is relaxed by distorting the high-coverage contract. Roughly speaking, the $(\mathrm{EH})$ constraint is the only one that prevents the insurer from raising the premium of the low-coverage contract (as doing that would not violate the other binding constraint $\left.\left(\mathrm{IG}_{\mathrm{l}}\right)\right)$. Hence, relaxing the $(\mathrm{EH})$ constraint allows the insurer to reduce the ex ante consumer rent by charging a higher premium for the low-coverage contract.

In some sense, our distortion result is similar to the result in moral hazard models in which the optimal contract is distorted in order to discourage an action that would hurt the principal - for example, shirking in a labor contract. The undesirable action in our model is information gathering: The distortion of the high-coverage contract makes the two contracts more similar-that is, $\left(\bar{u}_{l}-\underline{u}_{l}\right)-\left(\bar{u}_{h}-\underline{u}_{h}\right)$ gets smaller-and therefore reduces the optimal effort (see (5)). Why does effort hurt the insurer? The reason is that the insurer's profits are, ceteris paribus, decreasing in effort (the profits are $\pi=\sum_{i \in\{l, h\}} \alpha_{i}\left[p_{i}-\beta_{i}(e) R_{i}\right]$, and hence $\left.\partial \pi / \partial e=-\alpha_{h} \beta_{h}^{\prime}(e)\left(R_{h}-R_{l}\right)<0\right)$.

To get some intuition for why the insurer's profits decrease in effort, consider a standard Stiglitz model without information gathering. There, a fraction $\alpha_{h}$ of consumers have high risk and will, in equilibrium, buy a high-coverage contract at a high premium. A fraction $\alpha_{l}$ of consumers have a low risk and buy a low-coverage contract at a low premium. In this situation, suppose the insurer could convince a high-risk consumer and a low-risk consumer to swap contracts. This would increase the insurer's expected profits: Revenues would remain the same but expected costs would be lower because the swapping implies that the high-risk consumer who suffers the accident more often has a lower coverage.

In the standard Stiglitz model the insurer can, of course, not convince consumers to swap contracts. But in our model with endogenous information acquisition, exerting less effort is in its effect very similar to swapping contracts: Less information acquisition means that consumers are more likely to receive a signal that does not correspond to their true risk type - that is, a larger number of high-risk consumers buy the lowcoverage contract, and vice versa. Consequently, the insurer's profits are higher if consumers exert less effort.

In short, distorting the high-coverage contract reduces the extent of information gathering as the two contracts become more similar. Consumers are therefore more likely to sort themselves into the "wrong" insurance contract. We call this effect the missorting effect: The insurer benefits from keeping consumers uninformed (as they then missort into the "wrong" contract) and distorting the top contract leads to less informed consumers.

The distortion result of proposition 1 does not appear in the previous literature 
that has endogenized the information structure in screening models. ${ }^{17}$ There are two main reasons why we obtain a different result in our model. First, our effort variable is continuous, in contrast to most of the previous literature which assumes a binary effort decision (see, e.g., Crémer et al. (1998)); in the latter setting, the logic that gives rise to distortion at the top in our setting cannot arise: There is neither an (EH) constraint which could be relaxed nor the possibility of marginally reducing information acquisition by distorting the top contract. ${ }^{18}$ Second, we consider an insurance problem. In a standard procurement problem, there is no missorting effect because the principal's payoff does not directly depend on the agent's type (there is only an indirect dependence through the contract choice), while in an insurance problem the agent's type determines the insurer's expected expenditures.

Apart from the distortion, the optimal effort level is of economic interest. Given the optimal contract menu, the optimal effort is uniquely determined by (5). Unfortunately, because the insurer's menu choice problem is not quasiconcave, it is hard to obtain general results concerning the level of effort . The following proposition gives results for certain limit cases. To state limit results with respect to the information acquisition cost, we write the cost function as $\gamma c(e)$ instead $c(e)$, where $\gamma>0$. All three results are understood ceteris paribus, meaning that the not mentioned parameters are treated as fixed.

Proposition 2. The following limit results hold:

(i) The equilibrium effort level approaches zero as the prior probability of a low-risk type, $\alpha_{l}$, approaches one.

(ii) The equilibrium effort level becomes arbitrarily large as $\gamma$ approaches zero. Furthermore, the equilibrium contract menu approaches the Stiglitz menu with types $\left\{\lim _{e \rightarrow \infty} \beta_{h}(e), \lim _{e \rightarrow \infty} \beta_{l}(e)\right\}$ as $\gamma$ approaches zero.

(iii) The equilibrium effort level approaches zero as $\gamma$ approaches $\infty$. Furthermore, the coverage levels of both contracts approach full coverage as $\gamma$ approaches $\infty$.

\footnotetext{
${ }^{17}$ The notable exception we are aware of is a result in an extension of Szalay's (2009) main analysis in which he allows for a moving support. That is, the choice of effort affects the possible range of expected marginal costs. Distortion at the top will then have an impact on the effort choice. This affects the support, which in turn changes the agent's expected rent and therefore the principal's payoff.

${ }^{18}$ In the pooling case (i.e., when it is optimal with no information acquisition), Cremer et al. (1998) also obtain a distorted contract. The reason is that this distortion relaxes the binding information acquisition constraint which, in the case of pooling, is similar to our (EH) constraint.
} 


\section{Policy intervention: Information provision}

In this section, we address the policy questions that we raised in the introduction. As we explained there, it is common to hear claims from policymakers and commentators that well-informed consumers make markets work better and are therefore good for welfare. Often, the ambition of these policymakers is to empower consumers, and key elements of this empowerment are to provide information to and facilitate information acquisition by consumers. For example, the E.U. Consumer Policy Strategy 2007-2013 states in its objectives that "Empowered consumers need real choices, accurate information, market transparency and the confidence that comes from effective protection and solid rights" (our italics). ${ }^{19}$ We will here, within the framework of the model studied in the previous sections, investigate the welfare implications of a policy that lowers the consumers' cost of gathering information about their health risks.

In this section, we will denote the effort cost function not by $c(e)$ but by $\gamma c(e)$, with $\gamma>0$. We will think of "a policy that facilitates for consumers to gather information" as a policy that lowers $\gamma$. The question we will ask is: Given the equilibrium menu of insurance policies, what is the effect on consumer surplus and on the insurer's profits of an (exogenous) reduction in $\gamma ?^{20}$

A first answer to that question is given by the numerical example that we studied in section 5.2 (see also Appendix B). Figure 4 plots the values of the insurer's profits and the consumer surplus that the example gives rise to, for a range of different values of the cost parameter $\gamma$ (from $\gamma=0.05$ to $\gamma=1.3$ ). The example in figure 4 shows that, in general, the effect of a reduction in $\gamma$ on consumer surplus is ambiguous: It can be either positive or negative. In particular, figure 4 shows that both the consumer and the insurer can be hurt by a reduction in the cost. The more surprising of these results is probably the one saying that consumer surplus can decrease as a consequence of a reduction in $\gamma$. As information acquisition becomes less difficult, consumers benefit directly through the effect on their costs. However, there is also an indirect effect that goes through the conditions of the optimally chosen insurance policy. As it becomes easier for the consumer to learn about his risk, the constraints in the insurer's maximization problem are modified. In particular, the constraint (EH) will be harder to satisfy. To deal with this, the insurer adjusts the menu of insurance policies, which sometimes can have an

\footnotetext{
${ }^{19}$ European Commission (2007, p. 13). See also the quotes in the introduction and in footnote 1.

${ }^{20}$ Note that this means that we abstract from any "investment costs" that the policymaker may have to incur in order to facilitate for consumers to gather information (e.g., costs of funding an information campaign, leaflets, or a website). If we find that the net welfare effect is negative when not counting such investments costs, then it is of course even more so if including those costs.
} 


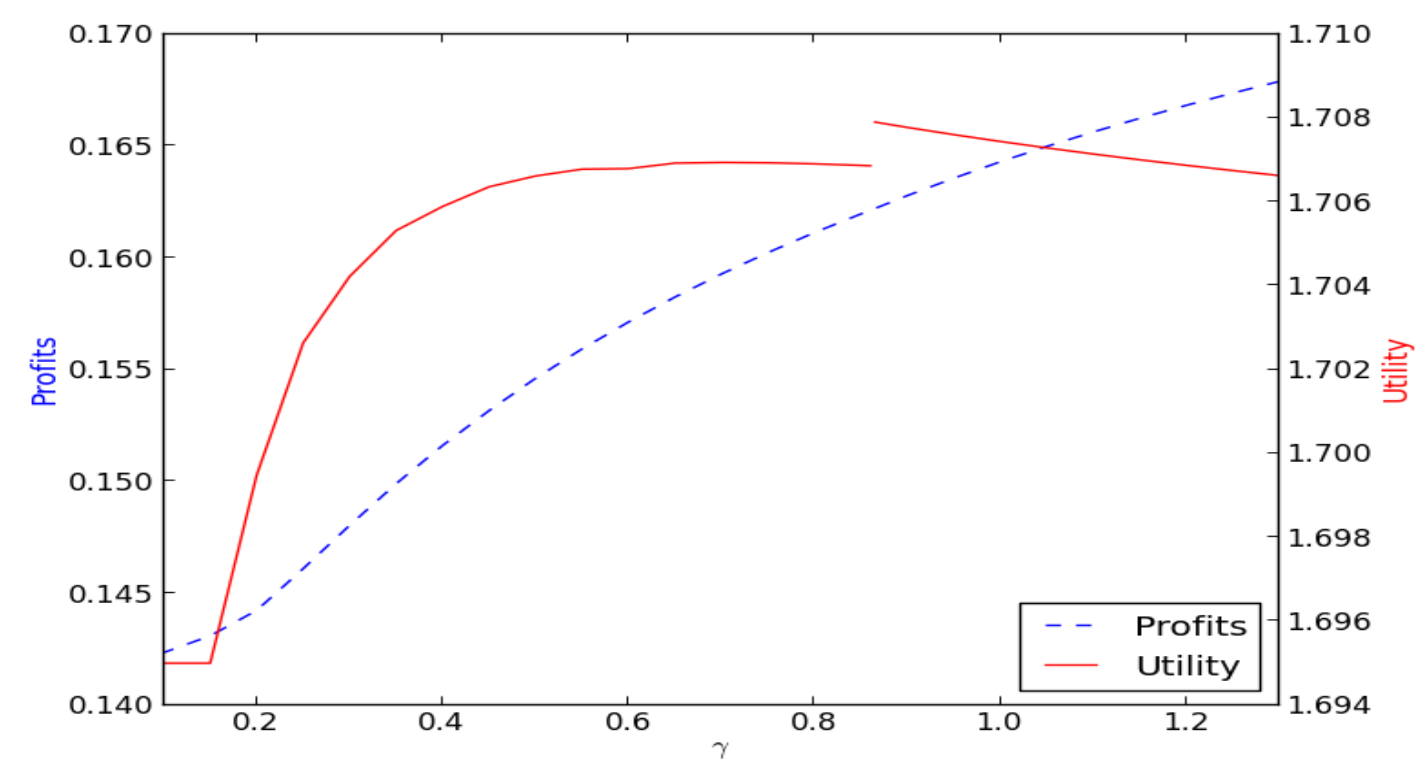

Figure 4: Consumer surplus and profits (numerical example)

adverse effect on consumer surplus. This is especially apparent around $\gamma=0.86$ in the figure, where the equilibrium type changes from separating to pooling (i.e., at that value of $\gamma$, the global maximum of the principal's objective function changes from one local maximum to another). Hence, contracts and consumer surplus change discontinuously in $\gamma$ at this point. ${ }^{21}$

Our welfare results are, to some extent, related to the so-called Hirshleifer effect (Hirshleifer, 1971). This effect refers to the phenomenon that risk sharing opportunities (or, more generally, opportunities to trade) can be eliminated if additional information becomes available - in an insurance setting, information about the future accident risk makes the risk uninsurable. In our model, a smaller $\gamma$ increases the incentive to gather information, which means that additional information indeed becomes available. However, information acquisition is endogenous in our setting, in contrast to most of the settings where the Hirshleifer effect is discussed. In particular, the consumer's choice of $e$ is private. This creates the opportunity for the consumer, when choosing $e$, to make a unilateral and non-observable deviation from the insurer's recommendation. In order to disincentivize any such deviation, the insurer must ensure that the information gathering constraints hold-including $\left(\mathrm{IG}_{1}\right)$ and $(\mathrm{EH})$, which both bind at the equilibrium. These binding constraints help determine the nature of the equilibrium contracts

\footnotetext{
${ }^{21}$ The equilibrium type is exclusionary for $\gamma$ between zero and about 0.16 (i.e., where the solid graph is flat); it is pooling for $\gamma$ above 0.86 ; and it is separating for all the intermediate values of $\gamma$.
} 
and thus contribute to the welfare results reported above. That is, our welfare results are not driven only by a change in the amount of information directly, but also by the indirect effect of the change in $\gamma$ on the equilibrium contract menu (through the binding information gathering constraints). ${ }^{22}$

Another related effect occurs in the auction literature. Fang and Morris (2006, section 6.2) analyze an independent private value auction in which bidders can buy an imperfect signal about their competitor's valuation. They show that bidder surplus and welfare can decrease in the first price auction if the cost of the signal decreases. The reasons are that (i) the cost is incurred and (ii) the bidders' strategies change if they get information (in particular, bidding becomes more aggressive). While this effect is similar to ours, the setup is quite different: The acquired information is not about own preferences but concerns other players' preferences, players are symmetric, and they compete with each other after the information acquisition.

Although the effects of a change in $\gamma$ on consumer surplus and profits are ambiguous in general, clear-cut results emerge in special cases.

Proposition 3. (i) If the equilibrium contract menu is exclusionary, consumer surplus is constant in $\gamma$. (ii) If the equilibrium contract menu is pooling, profits are increasing in $\gamma$.

Part (i) of proposition 3 says that in an equilibrium with exclusion (meaning that the consumer exerts some positive effort and then buys an insurance only if receiving a high signal) a change in the information acquisition cost has no impact on the consumer's expected utility. The reason for this is that in this kind of equilibrium the binding constraint $\left(\mathrm{IG}_{1}\right)$ becomes the ex ante individual rationality constraint (see our discussion in section 5.1), which means that the consumer does not receive any ex ante rents. Since the consumer's outside option is independent of $\gamma$, a change in this parameter cannot

\footnotetext{
${ }^{22}$ In the part of the insurance literature that studies the value of information (see, e.g., Doherty and Thistle (1996, p. 94) and Crocker and Snow (2013)), another welfare effect is sometimes discussed, namely an effect due to a so-called classification risk. This term refers to the uncertainty that is created by the introduction of a classification procedure (in our context, the introduction of insurance contracts that are contingent on consumer type); this uncertainty imposes a cost on a risk averse consumer, given that he evaluates his expected welfare at a point in time when he has not yet learned his type/classification. This effect can thus create a disincentive for a consumer to acquire information about his type, if also the insurer learns the information and can make the insurance policy contingent on it. As already pointed above, however, in our setting information acquisition is by assumption private. This means that if the consumer makes a unilateral deviation from the insurer's recommended $e$, then this cannot have any impact on the set of available contracts. Hence, in our model, the welfare effect associated with the classification risk does not play any role in the consumer's information gathering decision.
} 
affect his expected equilibrium utility. In other words, while the reduction in $\gamma$ lowers the consumer's effort costs, the insurer also makes the conditions in the insurance contract less favorable to the consumer, leaving the net effect equal to zero.

Next consider part (ii) of proposition 3. The effect of a change in $\gamma$ on profits consists, in general, of three parts. First, a lower $\gamma$ tightens the constraint (EH): Deviating to the high effort level $e^{h}$ becomes more attractive when the cost is relatively low. Second, a lower $\gamma$ relaxes the constraint $\left(\mathrm{IG}_{1}\right)$ : While the utility from simply buying contract $l$ (with zero effort) is not affected, the costs of exerting effort $e$ are lower and therefore the expected utility from the contracts in the menu is higher. Third, due to the missorting effect that we have discussed above, a reduction in $\gamma$ lowers profits: A lower value of $\gamma$ leads to higher effort $e$ and therefore a more precise signal, which is bad for the insurer's profits. In an equilibrium with pooling, only the first of these three effects is non-zero. As a consequence, a reduction in $\gamma$ decreases profits.

\section{Concluding discussion}

In this paper, we have studied a monopoly insurance model with endogenous information acquisition. We assumed that the insurer and the consumer are initially symmetrically informed about the latter's risk status. However, the consumer can, privately and covertly, learn more about his risk by exerting costly effort. This effort choice is continuous.

In our model, we assumed that the consumer's information acquisition cost entered his payoff additively, rather than being subtracted from his wealth and thus entering the argument of the utility function. One interpretation of this model specification, which would justify our modeling choice, is that the cost is not a monetary expenditure but a disutility of effort. The assumption that the cost is additive has been made before (see Doherty and Thistle, 1996) and makes our analysis much more tractable than it would otherwise be. Still, a natural question is whether, or to what extent, our results would be altered if we assumed that the cost of effort were monetary and therefore entered the argument of the consumer's utility function. We explore this question in the supplementary material to this paper. We there show that our main results hold for the case of CARA preferences (which imply that there are no income effects on risk aversion). For other utility specifications, the analysis becomes intractable as the endogenous extent of information acquisition can change the degree of risk aversion and therefore the demand for insurance.

The insurance company in our model is a monopolist. While admittedly this does not reflect the reality in all insurance markets, insurance companies tend to be big 
due to scale economies in risk diversification. Recent empirical evidence (Dafny, 2010) shows that health insurance companies in the U.S. indeed have market power. In smaller countries with more public involvement in health care than in the U.S., health insurers will typically have even more market power. In Denmark, for example, a public system that is funded by taxes covers basic health care. However, dental care, physiotherapy, chiropractors and care in private hospitals are not covered by the public system. Instead there is a private insurance company (Sygeforsikringen "danmark" g.s.) that offers additional health insurance for these services. This company is indeed a monopolist in its market and it offers a menu of insurance policies with different levels of coverage.

Still, it is a natural to wonder whether our results would generalize to an oligopoly setting or to a setting with perfect competition. In the supplementary material, we explore both these alternative settings. We there use a relatively simple and standard approach for capturing perfect competition, namely, to replace the single monopolist with a large number of insurers and then assume that these play a so-called RothschildStiglitz (1976) equilibrium. In such an equilibrium, the firms offer menus such that (i) each contract in the menu makes non-negative profits and (ii) no insurer can make positive profits by offering an additional contract given that this menu is offered. The consumer side of the perfect competition model is the same as in our original model. We show that in any Rothschild-Stiglitz equilibrium, provided that it exists, all contracts are distorted downwards. In the supplementary material we also study a simple Hotellinglike oligopoly model, and we show that also in this setting all contracts are distorted. These findings suggest that the result reported in proposition 1 of the current paper is not driven by the monopoly assumption but is a more general property of insurance models with endogenous information acquisition, which holds across different market structures.

In our model, we present the following results: (i) Depending on parameter values, the equilibrium of the model can involve zero effort (meaning symmetric information) or a positive effort (which implies a privately informed consumer). (ii) Regardless of the nature of the equilibrium, all contracts, also at the top, involve underinsurance. (iii) In the limit where the information acquisition cost approaches zero, the equilibrium outcome approaches the one in Stiglitz's (1977) classic model. (iv) An exogenous reduction in the information acquisition cost has, for certain parameter values, a negative effect both on profits and consumer surplus. (v) For other parameter values, a reduction in the cost can be beneficial. Hence, welfare results are ambiguous in general.

We also identify a missorting effect that implies that the insurer wants the consumer to be badly informed. This effect is an important reason behind our result that there is underinsurance also at the top. The logic is that a consumer with a relatively uninfor- 
mative signal is more likely to choose the "wrong" contract - the low-coverage contract if the true health risk is high, and the high-coverage contract if the true health risk is low. From the insurer's point of view, it is a good thing if the consumer tends to choose the wrong contract! The reason is that this lowers the expected value of the indemnities that the insurer must pay to the consumer. To see this think of a high-risk agent buying a high-coverage contract and of a low-risk agent buying a low-coverage contract. Now suppose the two agents swapped contracts. Then the revenue of the insurer remains the same but the expected indemnity expenditures decrease. This "swapping" is exactly what takes place if insurees have less information. We are not aware of any discussion of the missorting effect in the previous literature. The effect should show up in insurance settings quite generally, whenever the precision of the insuree's information is a continuum. However, the missorting effect does not appear in, for example, a procurement setting because the agent's type does not affect the principal's payoff directly in such a setting.

In terms of our original motivation, we can see that incorporating the possibility of information acquisition in an insurance model gives novel economic insights (e.g., the missorting effect). Traditional insurance models that treat information as exogenous are in some sense robust to the possibility of information acquisition: If the costs of information gathering are low, the optimal contracts in our model are close to those in the Stiglitz model. However, traditional models are not robust to the possibility of information acquisition in terms of qualitative predictions: With information acquisition there is always distortion at the top and the optimal contracts can be pooling. In the Stiglitz model, there is no distortion at the top and the optimal contract menu is never pooling. In terms of policy, we show that lowering the information acquisition costs has an ambiguous effect on welfare and consumer surplus. In particular, lower costs can lead to lower consumer welfare. 


\section{Appendix}

\section{A. Proofs}

\section{A.1. The Reduced-Form Problem}

We here provide a detailed formulation of the insurer's profit maximization problem. By lemma 1, the optimal menu of contracts solves the program stated in eq. (7) in the text. The constraints that are associated with the problem can be stated a follows:

$$
\begin{gathered}
\sum_{i \in\{l, h\}} \alpha_{i}\left[\beta_{i}(e) \underline{u}_{i}+\left(1-\beta_{i}(e)\right) \bar{u}_{i}\right]-c(e)=\beta \underline{u}_{l}+(1-\beta) \bar{u}_{l}, \\
\alpha_{h}\left[\left(\beta_{h}(e)-\beta_{h}\left(e^{h}\right)\right) \underline{u}_{h}+\left(\beta_{h}\left(e^{h}\right)-\beta_{h}(e)\right) \bar{u}_{h}\right]+\alpha_{l}\left[\beta_{l}(e) \underline{u}_{l}+\left(1-\beta_{l}(e)\right) \bar{u}_{l}\right]-c(e) \\
=\alpha_{l}\left[\beta^{l}\left(e^{h}\right) \underline{u}_{0}+\left(1-\beta_{l}\left(e^{h}\right)\right) \bar{u}_{0}\right]-c\left(e^{h}\right), \\
c^{\prime}(e)=\alpha \beta_{h}^{\prime}(e)\left(\bar{u}_{l}-\underline{u}_{l}-\bar{u}_{h}+\underline{u}_{h}\right), \\
c^{\prime}\left(e^{h}\right)=\alpha \beta_{h}^{\prime}\left(e^{h}\right)\left(\bar{u}_{0}-\underline{u}_{0}-\bar{u}_{h}+\underline{u}_{h}\right), \\
e^{h} \geq e \geq 0 .
\end{gathered}
$$

The equalities in (9) and (10) are the binding $\left(\mathrm{IG}_{1}\right)$ and $(\mathrm{EH})$ constraints, respectively. Since the constraints (9)-(12) are all linear in the agent's ex post utility levels, we can solve them for the four utility levels as functions of $e$ and $e^{h}$. This leads to the following expressions:

$$
\begin{aligned}
\bar{u}_{l}\left(e, e^{h}\right) & =\bar{u}_{0}-\beta_{l}\left(e^{h}\right) \frac{c^{\prime}\left(e^{h}\right)}{\alpha_{h} \beta_{h}^{\prime}\left(e^{h}\right)}+\beta_{l}(e) \frac{c^{\prime}(e)}{\alpha_{h} \beta_{h}^{\prime}(e)}-\frac{c\left(e^{h}\right)-c(e)}{\alpha_{l}} \\
\underline{u}_{l}\left(e, e^{h}\right) & =\underline{u}_{0}+\left(1-\beta_{l}\left(e^{h}\right)\right) \frac{c^{\prime}\left(e^{h}\right)}{\alpha_{h} \beta_{h}^{\prime}\left(e^{h}\right)}-\left(1-\beta_{l}(e)\right) \frac{c^{\prime}(e)}{\alpha_{h} \beta_{h}{ }^{\prime}(e)}-\frac{c\left(e^{h}\right)-c(e)}{\alpha_{l}} \\
\bar{u}_{h}\left(e, e^{h}\right) & =\bar{u}_{0}-\beta_{l}\left(e^{h}\right) \frac{c^{\prime}\left(e^{h}\right)}{\alpha_{h} \beta_{h}^{\prime}\left(e^{h}\right)}-\left[\beta_{h}(e)-\beta_{l}(e)\right] \frac{c^{\prime}(e)}{\alpha_{h} \beta_{h}^{\prime}(e)}-\frac{c\left(e^{h}\right)-c(e)}{\alpha_{l}}+\frac{c(e)}{\alpha_{h}} \\
\underline{u}_{h}\left(e, e^{h}\right) & =\underline{u}_{0}+\left(1-\beta_{l}\left(e^{h}\right)\right) \frac{c^{\prime}\left(e^{h}\right)}{\alpha_{h} \beta_{h}^{\prime}\left(e^{h}\right)}-\left[\beta_{h}(e)-\beta_{l}(e)\right] \frac{c^{\prime}(e)}{\alpha_{h} \beta_{h}^{\prime}(e)}-\frac{c\left(e^{h}\right)-c(e)}{\alpha_{l}}+\frac{c(e)}{\alpha_{h}}(1
\end{aligned}
$$

Plugging these expressions into the objective function (7) leads to a maximization problem over the two variables $e$ and $e^{h}$, where the only constraints are $e^{h} \geq e \geq 0$. An equilibrium with pooling results if $e=0$. An equilibrium with exclusion occurs if $e^{h}=e$. This is summarized in the following proposition.

Proposition A1. The optimal contract menu is given by (14), where e and $e^{h}$ solve the maximization problem stated in (8). The optimal contract menu satisfies the following 
first-order conditions:

$$
\begin{aligned}
\frac{\partial \pi\left(e, e^{h}\right)}{\partial e}= & -\alpha_{h} \beta_{h}^{\prime}(e)\left[h\left(\bar{u}_{l}\right)-h\left(\underline{u}_{l}\right)-h\left(\bar{u}_{h}\right)+h\left(\underline{u}_{h}\right)\right] \\
& -\alpha_{l} \beta_{l}(e)\left(1-\beta_{l}(e)\right)\left[h^{\prime}\left(\bar{u}_{l}\right)-h^{\prime}\left(\underline{u}_{l}\right)\right] \frac{c^{\prime \prime}(e) \beta_{h}^{\prime}(e)-\beta_{h}^{\prime \prime}(e) c^{\prime}(e)}{\alpha_{h}\left(\beta_{h}^{\prime}(e)\right)^{2}} \\
& +\alpha_{h}\left[\beta_{h}(e) h^{\prime}\left(\underline{u}_{h}\right)+\left(1-\beta_{h}(e)\right) h^{\prime}\left(\bar{u}_{h}\right)\right]\left[\beta_{h}(e)-\beta_{l}(e)\right] \frac{c^{\prime \prime}(e) \beta_{h}^{\prime}(e)-\beta_{h}^{\prime \prime}(e) c^{\prime}(e)}{\alpha_{h}\left(\beta_{h}^{\prime}(e)\right)^{2}} \\
\leq & 0 \quad \text { with " }=\text { " if e }>0 ; \\
\frac{\partial \pi\left(e, e^{h}\right)}{\partial e^{h}=} & {\left[\alpha_{h}\left(-\beta_{h}(e) h^{\prime}\left(\underline{u}_{h}\right)\left(1-\beta_{l}\left(e^{h}\right)\right)+\left(1-\beta_{h}(e)\right) h^{\prime}\left(\bar{u}_{h}\right) \beta_{l}\left(e^{h}\right)\right)\right.} \\
& \left.+\alpha_{l}\left(-\beta_{l}(e) h^{\prime}\left(\underline{u}_{l}\right)\left(1-\beta_{l}\left(e^{h}\right)\right)+\left(1-\beta_{l}(e)\right) h^{\prime}\left(\bar{u}_{l}\right) \beta_{l}\left(e^{h}\right)\right)\right] \times \\
& \frac{c^{\prime \prime}\left(e^{h}\right) \beta_{h}^{\prime}\left(e^{h}\right)-\beta_{h}^{\prime \prime}\left(e^{h}\right) c^{\prime}\left(e^{h}\right)}{\alpha_{h}\left(\beta_{h}^{\prime}\left(e^{h}\right)\right)^{2}} \\
\leq & 0 \quad \text { with “=”if } e^{h}>e ; \\
e^{h} \geq & e \geq 0,
\end{aligned}
$$

where the $\bar{u}_{i}$ and $\underline{u}_{i}$ are given by (14).

To illustrate some of the insurer's incentives when designing the optimal menu, consider the effect on the profits of an increase in the effort level $e$, i.e., the left-hand side of (15). The first part of the derivative, on the first line, is strictly negative as long as the coverage of contract $h$ is strictly higher than that of contract $l$. This part represents the missorting effect discussed in the text. The remaining part of the expression, on the second and third lines, represents the effect on the insurer's profit that goes via changes in the ex post utility levels in (14). For example, a higher $e$ requires an increase in $\left(\bar{u}_{l}-\underline{u}_{l}\right)-\left(\bar{u}_{h}-\underline{u}_{h}\right)$ (see eq. (5)). And a larger $\left(\bar{u}_{l}-\underline{u}_{l}\right)-\left(\bar{u}_{h}-\underline{u}_{h}\right)$, in turn, relaxes $\left(\mathrm{IG}_{1}\right)$, which enables the insurer to lower the utility levels in contract $h$ and thus increase profits. This second part of (15) can therefore be positive, making it profitable for the insurer to induce a positive effort level.

\section{A.2. The Other Proofs}

Proof of lemma 1: First, $\left(\mathrm{IC}_{\mathrm{h}}\right)$ is implied by $\left(\mathrm{IG}_{1}\right)$. Recall that $\beta=\alpha_{h} \beta_{h}(e)+\alpha_{l} \beta_{l}(e)$. Consequently, $\left(\mathrm{IG}_{1}\right)$ can be rewritten as

$$
\beta_{h}(e) \underline{u}_{h}+\left(1-\beta_{h}(e)\right) \bar{u}_{h}-\beta_{h}(e) \underline{u}_{l}-\left(1-\beta_{h}(e)\right) \bar{u}_{l} \geq c(e) / \alpha_{h},
$$

which is (weakly) more stringent than $\left(\mathrm{IC}_{\mathrm{h}}\right)$ as $c(e) / \alpha_{h} \geq 0$.

Second, $\left(\mathrm{IR}_{\mathrm{l}}\right)$ is slack. Suppose $\left(\mathrm{IR}_{\mathrm{l}}\right)$ was binding. We will show that in this case $(\mathrm{EH})$ would be violated. Given that $\left(\mathrm{IR}_{\mathrm{l}}\right)$ holds with equality, $(\mathrm{EH})$ can be written as $f(e) \geq f\left(e^{h}\right)$ where

$f(e)=\alpha_{h}\left[\left(\beta_{h}(e)-\beta_{h}\left(e^{h}\right)\right) \underline{u}_{h}+\left(\beta_{h}\left(e^{h}\right)-\beta_{h}(e)\right) \bar{u}_{h}\right]+\alpha_{l}\left[\beta_{l}(e) \underline{u}_{0}+\left(1-\beta_{l}(e)\right) \bar{u}_{0}\right]-c(e)$. 
Since $f$ is strictly concave in $e$ and since $e^{h}$ is defined as the maximizer of $f$, the inequality $f(e) \geq f\left(e^{h}\right)$ cannot hold and therefore $(\mathrm{EH})$ would be violated if $\left(\mathrm{IR}_{1}\right)$ was binding. Consequently, $\left(\mathrm{IR}_{\mathrm{l}}\right)$ cannot bind.

Third, $\left(\mathrm{IG}_{\mathrm{l}}\right)$ is binding in equilibrium. Note that the statement is tautological in an equilibrium with pooling, as in that case $\left(\mathrm{IG}_{1}\right)$ reduces to an identity. Thus consider an equilibrium with separation or exclusion and suppose that $\left(\mathrm{IG}_{1}\right)$ is not binding. If so, the insurer can decrease $\underline{u}_{h}$ by $\varepsilon>0$, which increases the profits. ${ }^{23}$ This deviation relaxes (or does not affect) all the other potentially binding constraints. The change will decrease the expected utility of the agent by $\alpha_{h} \beta_{h}(e) \varepsilon{ }^{24}$ This is less than $\alpha_{h} \beta_{h}\left(e^{h}\right) \varepsilon$ with $e^{h}>e$. Consequently, $(\mathrm{EH})$ is relaxed by the change. Similarly, $\left(\mathrm{IG}_{\mathrm{h}}\right)$ is relaxed as the effect on the right-hand side of $\left(\mathrm{IG}_{\mathrm{h}}\right)$ is $\beta=\alpha_{h} \beta_{h}(e)+\alpha_{l} \beta_{l}(e)>\alpha_{h} \beta_{h}(e)$. Therefore, $\left(\mathrm{IG}_{\mathrm{l}}\right)$ must bind.

Fourth, $\left(\mathrm{IG}_{\mathrm{h}}\right)$ is slack in the optimal contract. Suppose $\left(\mathrm{IG}_{\mathrm{h}}\right)$ was binding. We will show that the principal can deviate to a pooling contract that satisfies all constraints and increases profits. We distinguish two cases.

In the first case, assume $\bar{u}_{h}>\underline{u}_{h}$. In this case, we claim that profits can be increased by only offering contract $h$, i.e., by dropping contract $l$ from the menu. Since $\left(\mathrm{IG}_{\mathrm{h}}\right)$ was binding, the agent can achieve the same utility as before by buying contract $h$ without exerting effort. This must be his optimal choice, as reducing his choice set cannot result in higher ex ante utility. In particular, $(\mathrm{EH})$ is not affected and $\left(\mathrm{IG}_{1}\right)$ is irrelevant in the pooling situation. Now we must show that profits are increased. Denote by $h$ the inverse function of $u$. As $u$ is strictly concave, $h$ is strictly convex. Thus, ${ }^{25}$

$$
\begin{aligned}
\pi^{p} & =w-\beta D-\beta h\left(\underline{u}_{h}\right)-(1-\beta) h\left(\bar{u}_{h}\right) \\
& =w-\beta D-\alpha_{h}\left[\beta_{h}(e) h\left(\underline{u}_{h}\right)+\left(1-\beta_{h}(e)\right) h\left(\bar{u}_{h}\right)\right]-\alpha_{l}\left[\beta_{l}(e) h\left(\underline{u}_{h}\right)+\left(1-\beta_{l}(e)\right) h\left(\bar{u}_{h}\right)\right] \\
& >w-\beta D-\alpha_{h}\left[\beta_{h}(e) h\left(\underline{u}_{h}\right)+\left(1-\beta_{h}(e)\right) h\left(\bar{u}_{h}\right)\right]-\alpha_{l}\left[\beta_{l}(e) h\left(\underline{u}_{l}\right)+\left(1-\beta_{l}(e)\right) h\left(\bar{u}_{l}\right)\right]
\end{aligned}
$$

where the inequality follows from $\left(\mathrm{IC}_{1}\right)$ and the strict convexity of $h$. More specifically, the line between $h\left(\underline{u}_{l}\right)$ and $h\left(\bar{u}_{l}\right)$ is strictly above the line connecting $h\left(\underline{u}_{h}\right)$ and $h\left(\bar{u}_{h}\right)$, because $h$ is strictly convex and $\underline{u}_{l}<\underline{u}_{h}<\bar{u}_{h}<\bar{u}_{l}$. By $\left(\mathrm{IC}_{l}\right), \beta_{l}(e) \underline{u}_{l}+\left(1-\beta_{l}(e)\right) \bar{u}_{l} \geq$ $\beta_{l}(e) \underline{u}_{h}+\left(1-\beta_{l}(e)\right) \bar{u}_{h}$. Therefore, $\beta_{l}(e) h\left(\underline{u}_{l}\right)+\left(1-\beta_{l}(e)\right) h\left(\bar{u}_{l}\right)>\beta_{l}(e) h\left(\underline{u}_{h}\right)+(1-$ $\left.\beta_{l}(e)\right) h\left(\bar{u}_{h}\right)$. This concludes the proof for the case $\bar{u}_{h}>\underline{u}_{h}$.

For the second case, assume $\bar{u}_{h} \leq \underline{u}_{h}$. Then a full coverage pooling contract that

\footnotetext{
${ }^{23}$ The indirect effect of this change is that the optimal $e$ will be decreased. This indirect effect increases profits as well.

${ }^{24}$ The indirect effect through $e$ is negligible for $\varepsilon$ small enough, as the agent maximizes utility over $e$; that is, there is no first order effect.

${ }^{25}$ The first line below is an equivalent way of writing $p-\beta R$, i.e., the insurer's expected profits.
} 
gives the same ex ante utility to the agent increases profits and is feasible. Let $u_{p}=$ $\alpha_{h}\left[\beta_{h}(e) \underline{u}_{h}+\left(1-\beta_{h}(e)\right) \bar{u}_{h}\right]+\alpha_{l}\left[\beta_{l}(e) \underline{u}_{l}+\left(1-\beta_{l}(e)\right) \bar{u}_{l}\right]-c(e)$ be the utility level of the full coverage deviation contract. The agent can achieve the same utility level as before by buying the pooling contract without exerting effort. Hence, $\left(\mathrm{IG}_{1}\right)$, which turns into the ex ante individual rationality constraint under pooling, is satisfied. Because $\left(\mathrm{IG}_{\mathrm{h}}\right)$ was binding initially by assumption, we have $u_{p}=\beta \underline{u}_{h}+(1-\beta) \bar{u}_{h}$. As $\beta_{h}\left(e^{h}\right)>\beta$ and $\bar{u}_{h} \leq \underline{u}_{h}$, it follows that $u_{p}<\beta_{h}\left(e^{h}\right) \underline{u}_{h}+\left(1-\beta_{h}\left(e^{h}\right)\right) \bar{u}_{h}$. Therefore, (EH) is relaxed by the deviation. Finally, we show that profits are higher under the deviation contract:

$$
\begin{aligned}
\pi_{p} & =w-\beta D-h\left(u_{p}\right) \\
& =w-\beta D-h\left[\alpha_{h}\left(\beta_{h}(e) \underline{u}_{h}+\left(1-\beta_{h}(e)\right) \bar{u}_{h}\right)+\alpha_{l}\left(\beta_{l}(e) \underline{u}_{l}+\left(1-\beta_{l}(e)\right) \bar{u}_{l}\right)-c(e)\right] \\
& \geq w-\beta D-h\left[\alpha_{h}\left(\beta_{h}(e) \underline{u}_{h}+\left(1-\beta_{h}(e)\right) \bar{u}_{h}\right)+\alpha_{l}\left(\beta_{l}(e) \underline{u}_{l}+\left(1-\beta_{l}(e)\right) \bar{u}_{l}\right)\right] \\
& >w-\beta D-\alpha_{h}\left[\beta_{h}(e) h\left(\underline{u}_{h}\right)+\left(1-\beta_{h}(e)\right) h\left(\bar{u}_{h}\right)\right]-\alpha_{l}\left[\beta_{l}(e) h\left(\underline{u}_{l}\right)+\left(1-\beta_{l}(e)\right) \bar{u}_{l}\right],
\end{aligned}
$$

where the first inequality follows from $h^{\prime}>0$ and $c(e) \geq 0$ and the second inequality follows from $h^{\prime \prime}>0$.

Last, (EH) must be binding. If not, $\bar{u}_{l}$ and $\underline{u}_{l}$ could both be decreased by $\varepsilon>0$. This would not affect the optimal choice of $e$ and it would increase the principal's profit. The binding constraint $\left(\mathrm{IG}_{1}\right)$ would also be relaxed by this decrease.

Proof of proposition 1: We will first prove that contract $h$ cannot have full coverage when the equilibrium menu involves separation. Since contract $l$ by construction has less coverage than contract $h$, also contract $l$ must involve underinsurance. We will show that for any full coverage contract aimed at the high type, there is a partial coverage contract that (i) yields higher profits for the insurer, (ii) is preferred by the high type, and (iii) is feasible. We begin by computing the slope of the isoprofit curve in the $\left(\underline{u}_{h}, \bar{u}_{h}\right)$-plane (while keeping $\underline{u}_{l}$ and $\bar{u}_{l}$ fixed). Using the profit expression stated in (7) and invoking the implicit function theorem (acknowledging that also $e$ depends on $\underline{u}_{h}$ through the optimality condition in (11)), we obtain the following expression for the slope of the isoprofit curve:

$$
\begin{aligned}
& \left.\frac{d \bar{u}_{h}}{d \underline{u}_{h}}\right|_{\frac{\pi}{\pi}} \\
= & -\frac{-\alpha_{h} \beta_{h}(e) h^{\prime}\left(\underline{u}_{h}\right)-\alpha_{h} \beta_{h}^{\prime}(e) \frac{d e}{d \underline{u}_{h}}\left[D+h\left(\underline{u}_{h}\right)-h\left(\bar{u}_{h}\right)\right]-\alpha_{l} \beta_{l}^{\prime}(e) \frac{d e}{d \underline{u}_{h}}\left[D+h\left(\underline{u}_{l}\right)-h\left(\bar{u}_{l}\right)\right]}{-\alpha_{h}\left[1-\beta_{h}(e)\right] h^{\prime}\left(\bar{u}_{h}\right)-\alpha_{h} \beta_{h}^{\prime}(e) \frac{d e}{d \bar{u}_{h}}\left[D+h\left(\underline{u}_{h}\right)-h\left(\bar{u}_{h}\right)\right]-\alpha_{l} \beta_{l}^{\prime}(e) \frac{d e}{d \bar{u}_{h}}\left[D+h\left(\underline{u}_{l}\right)-h\left(\bar{u}_{l}\right)\right]} \\
= & -\frac{\beta_{h}(e) h^{\prime}\left(\underline{u}_{h}\right)+\beta_{h}^{\prime}(e) \frac{d e}{d \underline{u}_{h}}\left(R_{h}-R_{l}\right)}{\left[1-\beta_{h}(e)\right] h^{\prime}\left(\bar{u}_{h}\right)-\beta_{h}^{\prime}(e) \frac{d e}{d \underline{u}_{h}}\left(R_{h}-R_{l}\right)} \\
< & -\frac{\beta_{h}(e) h^{\prime}\left(\underline{u}_{h}\right)}{\left[1-\beta_{h}(e)\right] h^{\prime}\left(\bar{u}_{h}\right)} .
\end{aligned}
$$


The second equality above makes use of $\alpha_{h} \beta_{h}^{\prime}(e)=-\alpha_{l} \beta_{l}^{\prime}(e)$ and $D+h\left(\underline{u}_{i}\right)-h\left(\bar{u}_{i}\right)=R_{i}$ as well as $-d e / d \bar{u}_{h}=d e / d \underline{u}_{h}>0$ (see (11) for the latter). The inequality follows from the fact that $\beta_{h}^{\prime}(e)>0, d e / d \underline{u}_{h}>0$ and $R_{h}>R_{l}$.

Next we calculate the slope of the high-type agent's indifference curve in the $\left(\underline{u}_{h}, \bar{u}_{h}\right)$ plane. The high type's expected utility from contract $h$ equals $E U^{h i g h}=\beta_{h}(e) \underline{u}_{h}+$ $\left(1-\beta_{h}(e)\right) \bar{u}_{h}$. By implicitly differentiating both sides of this identity with respect to $\underline{u}_{h}$, while acknowledging that also $e$ depends on $\underline{u}_{h}$ through the optimality condition in (11), we obtain the following expression for the slope:

$$
\begin{aligned}
\left.\frac{d \bar{u}_{h}}{d \underline{u}_{h}}\right|_{E U^{h i g h}=\mathrm{const}} & =-\frac{\beta_{h}(e)+\beta_{h}^{\prime}(e)\left(\underline{u}_{h}-\bar{u}_{h}\right) \frac{d e}{d \underline{u}_{h}}}{1-\beta_{h}(e)+\beta_{h}^{\prime}(e)\left(\underline{u}_{h}-\bar{u}_{h}\right) \frac{d e}{d \bar{u}_{h}}} \\
& =-\frac{\beta_{h}(e)+\beta_{h}^{\prime}(e)\left(\underline{u}_{h}-\bar{u}_{h}\right) \frac{d e}{d \underline{u}_{h}}}{1-\beta_{h}(e)-\beta_{h}^{\prime}(e)\left(\underline{u}_{h}-\bar{u}_{h}\right) \frac{d e}{d \underline{u}_{h}}},
\end{aligned}
$$

where the second equality uses $d e / d \bar{u}_{h}=-d e / d \underline{u}_{h}$. It follows that at the point where there is full coverage (i.e., where $\bar{u}_{h}=\underline{u}_{h}$ ), the isoprofit curve is steeper than the indifference curve (both are negatively sloped). The implication is that, by marginally moving the high type's contract along the indifference curve and toward the region with underinsurance, the insurer's profits increase. That is, given some arbitrary full insurance contract for the high type, there exist partial insurance contracts that are more profitable for the insurer and preferred by the agent. ${ }^{26}$ Finally we consider the question whether these partial insurance contracts are feasible. As they give a higher utility to the high type, offering such a contract instead of a full-coverage contract relaxes $\left(\mathrm{IG}_{1}\right)$. Moreover, as the partial-insurance contracts reduce coverage (i.e., lower $\underline{u}_{h}$ and higher $\bar{u}_{h}$ ) also $(\mathrm{EH})$ is relaxed. The remaining constraints are, by lemma 1 , implied by $(\mathrm{EH})$ and $\left(\mathrm{IG}_{\mathrm{l}}\right)$.

Note that the same derivation applies to an exclusionary equilibrium (with subscript 0 instead of $l$ and $\left.R_{0}=0\right)$.

Before turning to pooling equilibria, we show that overinsurance is not optimal in a separating or exclusion equilibrium. Suppose there is overinsurance: $\bar{u}_{h}<\underline{u}_{h}$. Call the optimal effort level under the (supposedly) optimal contract $e^{*}$. We will show that the principal has a profitable deviation: Change contract $h$ by decreasing $\underline{u}_{h}$ by $\varepsilon>0$ and increasing $\bar{u}_{h}$ by $\varepsilon^{\prime}>0$.

Define the effort level $e^{\prime}$ as the optimal effort level in the changed menu; that is, $e^{\prime}$ solves

$$
\alpha \beta_{h}^{\prime}\left(e^{\prime}\right)\left(\Delta_{l}-\bar{u}_{h}-\varepsilon^{\prime}+\underline{u}_{h}-\varepsilon\right)=c^{\prime}\left(e^{\prime}\right)
$$

\footnotetext{
${ }^{26}$ Using the envelope theorem, one can derive $\left.\frac{d \bar{u}_{h}}{d \underline{u}_{h}}\right|_{E U=c o n s t}=\frac{\beta_{h}(e)}{1-\beta_{h}(e)}$. Hence, the ex ante utility of the agent increases when changing to such a partial insurance contract.
} 
where $\Delta_{i} \equiv \bar{u}_{i}-\underline{u}_{i}$. Note that $e^{\prime}<e^{*}$. Choose $\varepsilon^{\prime}$ such that the expected utility of the agent is not affected by the contract change:

$$
\begin{array}{r}
\alpha_{h}\left(\beta_{h}\left(e^{*}\right) \underline{u}_{h}+\left(1-\beta_{h}\left(e^{*}\right)\right) \bar{u}_{h}\right)+\alpha_{l}\left(\beta_{l}\left(e^{*}\right) \underline{u}_{l}+\left(1-\beta_{l}\left(e^{*}\right)\right) \bar{u}_{l}\right)-c\left(e^{*}\right) \\
=\alpha_{h}\left(\beta_{h}\left(e^{\prime}\right)\left(\underline{u}_{h}-\varepsilon\right)+\left(1-\beta_{h}\left(e^{\prime}\right)\right)\left(\bar{u}_{h}+\varepsilon^{\prime}\right)\right)+\alpha_{l}\left(\beta_{l}\left(e^{\prime}\right) \underline{u}_{l}+\left(1-\beta_{l}\left(e^{\prime}\right)\right) \bar{u}_{l}\right)-c\left(e^{\prime}\right) .
\end{array}
$$

Note that $\beta_{h}\left(e^{*}\right) \underline{u}_{h}+\left(1-\beta_{h}\left(e^{*}\right)\right) \bar{u}_{h}>\beta_{h}\left(e^{*}\right)\left(\underline{u}_{h}-\varepsilon\right)+\left(1-\beta_{h}\left(e^{*}\right)\right)\left(\bar{u}_{h}+\varepsilon^{\prime}\right)$ : If this was not the case, the agent would - under the modified menu - get an ex ante rent at least as high as in the original menu by exerting effort $e^{*}$. Choosing the optimal effort $e^{\prime}$ would then result in strictly higher ex ante utility, which contradicts the definition of $\varepsilon^{\prime}$. Using this insight, we show that profits are higher in the modified menu:

$$
\begin{aligned}
\pi^{\text {old }}= & \alpha_{h}\left[-\beta_{h}\left(e^{*}\right) D+w-\beta_{h}\left(e^{*}\right) h\left(\underline{u}_{h}\right)-\left(1-\beta_{h}\left(e^{*}\right)\right) h\left(\bar{u}_{h}\right)\right] \\
& +\alpha_{l}\left[-\beta_{l}\left(e^{*}\right) D+w-\beta_{l}\left(e^{*}\right) h\left(\underline{u}_{l}\right)-\left(1-\beta_{l}\left(e^{*}\right)\right) h\left(\bar{u}_{l}\right)\right] \\
< & \alpha_{h}\left[-\beta_{h}\left(e^{*}\right) D+w-\beta_{h}\left(e^{*}\right) h\left(\underline{u}_{h}-\varepsilon\right)-\left(1-\beta_{h}\left(e^{*}\right)\right) h\left(\bar{u}_{h}+\varepsilon^{\prime}\right)\right] \\
& +\alpha_{l}\left[-\beta_{l}\left(e^{*}\right) D+w-\beta_{l}\left(e^{*}\right) h\left(\underline{u}_{l}\right)-\left(1-\beta_{l}\left(e^{*}\right)\right) h\left(\bar{u}_{l}\right)\right] \\
\leq & \alpha_{h}\left[-\beta_{h}\left(e^{\prime}\right) D+w-\beta_{h}\left(e^{\prime}\right) h\left(\underline{u}_{h}-\varepsilon\right)-\left(1-\beta_{h}\left(e^{\prime}\right)\right) h\left(\bar{u}_{h}+\varepsilon^{\prime}\right)\right] \\
& +\alpha_{l}\left[-\beta_{l}\left(e^{\prime}\right) D+w-\beta_{l}\left(e^{\prime}\right) h\left(\underline{u}_{l}\right)-\left(1-\beta_{l}\left(e^{\prime}\right)\right) h\left(\bar{u}_{l}\right)\right] \\
= & \pi^{\text {new }} .
\end{aligned}
$$

The first inequality follows from the convexity of $h$ as well as $\beta_{h}\left(e^{*}\right) \underline{u}_{h}+\left(1-\beta_{h}\left(e^{*}\right)\right) \bar{u}_{h}>$ $\beta_{h}\left(e^{*}\right)\left(\underline{u}_{h}-\varepsilon\right)+\left(1-\beta_{h}\left(e^{*}\right)\right)\left(\bar{u}_{h}+\varepsilon^{\prime}\right)$ and the monotonicity of $h$. The second inequality follows from $\alpha_{h} \beta_{h}^{\prime}(e)=-\alpha_{l} \beta_{l}^{\prime}(e)$ (which implies that the expression is decreasing in $e$ ) and the fact that $e^{*}>e^{\prime}$.

Next we must show that no constraint is violated under the modified menu. As the ex ante expected utility and also the low-coverage contract did not change, $\left(\mathrm{IG}_{1}\right)$ is not affected by the modification of the menu. As $\left(\mathrm{IG}_{\mathrm{h}}\right)$ is slack under the optimal menu (see lemma 1), this constraint is not violated for small changes $\varepsilon$. To check (EH), define the function $z\left(\Delta_{h}\right)$ as

$$
\begin{aligned}
z\left(\Delta_{h}\right)= & \alpha_{h}\left[\beta_{h}\left(e^{h}\right)-\beta_{h}(e) \Delta_{h}\right]+\alpha_{l}\left[\beta_{l}(e) \underline{u}_{l}+\left(1-\beta_{l}(e)\right) \bar{u}_{l}\right]-c(e) \\
& -\alpha_{l}\left[\beta_{l}\left(e^{h}\right) \underline{u}_{0}-\left(1-\beta_{l}\left(e^{h}\right)\right) \bar{u}_{0}\right]+c\left(e^{h}\right),
\end{aligned}
$$

where $e$ and $e^{h}$ are also functions of $\Delta_{h}$ defined in the obvious manner through (5). The constraint $(\mathrm{EH})$ is satisfied if $z\left(\Delta_{h}\right) \geq 0$. Using the envelope theorem, we can compute $z^{\prime}\left(\Delta_{h}\right)=\alpha_{h}\left(\beta_{h}\left(e^{h}\right)-\beta_{h}(e)\right)>0$. Hence, increasing $\Delta_{h}$ relaxes (EH). As our modification increased $\Delta_{h}$, it also relaxes $(\mathrm{EH})$. The two remaining constraints $\left(\mathrm{IR}_{1}\right)$ and $\left(\mathrm{IC}_{\mathrm{h}}\right)$ are, by lemma 1 , implied by $(\mathrm{EH})$ and $\left(\mathrm{IG}_{1}\right)$. 
This shows that the modification of the menu increased profits while relaxing (or not affecting) the relevant constraints. Consequently, overinsurance cannot occur in a separating or exclusion equilibrium.

Last we consider a pooling equilibrium. Note that there cannot be overinsurance in a pooling equilibrium. The same argument as in the previous step (where the changes $\varepsilon$ and $\varepsilon^{\prime}$ apply to the pooling contract instead of contract $h$ ) shows this immediately.

It remains to show that full insurance is not optimal in a pooling equilibrium. There is only one binding constraint in a pooling equilibrium: The agent is indifferent between (i) zero effort and buying the contract and (ii) exerting positive effort and buying the contract only if he receives a high signal. The slope of the indifference curve of an agent exerting zero effort and buying a contract $(\bar{u}, \underline{u})$ is

$$
\left.\frac{d \bar{u}}{d \underline{u}}\right|_{E U=\mathrm{const}}=-\frac{\beta}{1-\beta},
$$

where $\beta=\alpha_{h} \theta^{h}+\alpha_{l} \theta^{l}$. The slope of the indifference curve of an agent exerting positive effort $e^{h}>0$ and buying the contract only when receiving a high signal is (when deriving this slope we use the fact that $e^{h}$ is chosen optimally and, therefore, the effect through $e^{h}$ is zero by the envelope theorem):

$$
\left.\frac{d \bar{u}}{d \underline{u}}\right|_{E U=\mathrm{const}}=-\frac{\beta_{h}\left(e^{h}\right)}{1-\beta_{h}\left(e^{h}\right)}<-\frac{\beta}{1-\beta},
$$

where the inequality follows from $\beta_{h}\left(e^{h}\right)>\beta$. Therefore, the indifference curve of the effort-exerting agent is steeper than the indifference curve of an agent with zero effort. This implies that-starting from a full coverage contract-there are partial coverage contracts that strictly relax the binding constraint. Furthermore, the slope of the isoprofit curve of the principal at a full coverage contract with zero effort is $\beta /(1-\beta)$. Therefore, for $\varepsilon>0$ small enough, a partial-coverage contract $(\widetilde{u}+\kappa \varepsilon, \widetilde{u}-\varepsilon)$ with $\kappa=\beta /(1-\beta)$ will (i) keep constant the utility of an agent who does not exert effort and buys the contract, (ii) will keep profits at the same level and (iii) strictly relax the binding $(\mathrm{EH})$ constraint. Therefore, there exists a partial-coverage contract $(\widetilde{u}+\kappa \varepsilon, \widetilde{u}-\varepsilon)$ with $\kappa$ slightly below $\beta /(1-\beta)$ such that the binding constraint is not violated while profits are higher than under the full-coverage contract $(\widetilde{u}, \widetilde{u})$. This shows that the contract in a pooling equilibrium will have partial coverage only.

Proof of proposition 2: See the supplementary material.

Proof of proposition 3: Part (i) is already proven in the main text.

Part (ii): Consider first the claim about the profits in the pooling case (where $e=0)$. Note that the only binding constraint $(\mathrm{EH})$ is relaxed if $\gamma$ is increased: Using the envelope theorem, the derivative with respect to $\gamma$ of the left-hand side is $-c(e)$ and 
the derivative of the right hand side is $-c\left(e^{h}\right)$. This means that a contract satisfying $(\mathrm{EH})$ for $\gamma^{\prime}$ will also satisfy (EH) for all $\gamma^{\prime \prime}>\gamma^{\prime}$. Hence, profits are non-decreasing in $\gamma$ as the set of feasible pooling contracts expands as $\gamma$ increases. Since (EH) is binding, profits are in fact increasing.

\section{B. Numerical example}

This section explains some details about the numerical example presented in table 1 . In this example, we use the linear signal technology $g(e)=\min \{e, 1\} .^{27}$ This gives us, for $e<1$,

$$
\beta_{h}(e)=\alpha_{h} \theta^{h}+\alpha_{l} \theta^{l}+\alpha_{l}\left(\theta^{h}-\theta^{l}\right) e, \quad \beta_{h}^{\prime}(e)=\alpha_{l}\left(\theta^{h}-\theta^{l}\right) .
$$

As the insurer's maximization program is not necessarily quasiconcave, we use a grid maximization where we search for the highest profits on a grid of 500 equally spaced effort levels between 0 and 1 (and an equally spaced grid for $e^{h}$ ). The result of this grid search is then given as starting value to a maximization algorithm. We use the "ralg" algorithm of the openopt package (http://openopt.org); see our websites for the Python code.

\footnotetext{
${ }^{27} \mathrm{As} g$ is non-differentiable at $e=1$ and flat thereafter, our assumptions are strictly speaking only satisfied if $e<1$. From the first-order condition (5), we can - with the here assumed functionsconclude that $e^{3}=\frac{\alpha(1-\alpha)\left(\theta^{h}-\theta^{l}\right)\left(\Delta_{l}-\Delta_{h}\right)}{4 \gamma}$. As $\Delta_{l}-\Delta_{h} \leq \Delta_{0}=1$ with our parameter values, $e^{3} \leq$ $\frac{0.007875}{\gamma}$ and therefore $e<1$ if $\gamma>0.007875$.
} 


\section{References}

BARdey, D. And P. De Donder, "Genetic Testing with Primary Prevention and Moral Hazard," Journal of Health Economics 32 (2013), 768-779.

Bergemann, D. And J. VÄlimäKi, "Information Acquisition and Efficient Mechanism Design," Econometrica 70 (2002), 1007-1033.

Crémer, J. AND F. Khalil, "Gathering Information Before Signing a Contract," American Economic Review 82 (1992), 566-578.

Crémer, J., F. Khalil And J. Rochet, "Contracts and Productive Information Gathering," Games and Economic Behavior 25 (1998), 174-193.

Crocker, K. J. And A. Snow, "The Theory of Risk Classification," in G. Dionne, ed., Handbook of Insurance, second edition, chapter 11 (Springer, 2013), 281-313.

Dafny, L., "Are Health Insurance Markets Competitive?," American Economic Review 100 (2010), 1399-1431.

Dionne, G., N. Fombaron And N. Doherty, "Adverse Selection in Insurance Contracting," in G. Dionne, ed., Handbook of Insurance, second edition, chapter 10 (Springer, 2013), 231-280.

Doherty, N. And P. Thistle, "Adverse Selection with Endogenous Information in Insurance Markets," Journal of Public Economics 63 (1996), 83-102.

European Commission, "EU Consumer Policy Strategy 2007-2013. Empowering Consumers, Enhancing Their Welfare, Effectively Protecting Them," Communication from the commission to the council, the European Parliament, and the European Economic and Social Committee. COM (2007) 99 (2007).

FAnG, H. AND S. Morris, "Multidimensional Private Value Auctions," Journal of Economic Theory 126 (2006), 1-30.

Hirshleifer, J., "The Private and Social Value of Information and the Reward to Inventive Activity," American Economic Review 61 (1971), 561-574.

Lagerlöf, J. N. M. And C. Schottmüller, "Facilitating Consumer Learning in Insurance Markets-What Are the Welfare Effects?," Mimeo, October 2014.

Ligon, J. A. AND P. D. Thistle, "Information Asymmetries and Informational Incentives in Monopolistic Insurance Markets," Journal of Risk and Insurance 63 (1996), 434-459. 
Persico, N., "Information Acquisition in Auctions," Econometrica 68 (2000), 135-148.

Peter, R., A. Richter And P. Thistle, "Endogenous Information and Adverse Selection under Loss Prevention," Mimeo, 2012.

Rothschild, M. And J. Stiglitz, "Equilibrium in Competitive Insurance Markets: An Essay on the Economics of Imperfect Information," Quarterly Journal of Economics 90 (1976), 629-649.

SHI, X., "Optimal Auctions with Information Acquisition," Games and Economic Behavior 74 (2012), 666-686.

Stiglitz, J. E., "Monopoly, Non-Linear Pricing and Imperfect Information: The Insurance Market," Review of Economic Studies 44 (1977), 407-430.

SzAlAy, D., "Contracts with Endogenous Information," Games and Economic Behavior 65 (2009), 586-625. 